\title{
A Speed Control Method for Underwater Vehicle under Hydraulic Flexible Traction
}

\author{
Yin Zhao, Ying-kai Xia, Ying Chen, and Guo-Hua Xu \\ School of Naval Architecture and Ocean Engineering, Huazhong University of Science and Technology, Wuhan 430074, China \\ Correspondence should be addressed to Guo-Hua Xu; hustxu@vip.sina.com
}

Received 3 June 2015; Revised 15 August 2015; Accepted 10 September 2015

Academic Editor: Pedro Castillo

Copyright (c) 2015 Yin Zhao et al. This is an open access article distributed under the Creative Commons Attribution License, which permits unrestricted use, distribution, and reproduction in any medium, provided the original work is properly cited.

\begin{abstract}
Underwater vehicle speed control methodology method is the focus of research in this study. Driven by a hydraulic flexible traction system, the underwater vehicle advances steadily on underwater guide rails, simulating an underwater environment for the carried device. Considering the influence of steel rope viscoelasticity and the control system traction structure feature, a mathematical model of the underwater vehicle driven by hydraulic flexible traction system is established. A speed control strategy is then proposed based on the sliding mode variable structure of fuzzy reaching law, according to nonlinearity and external variable load of the vehicle speed control system. Sliding mode variable structure control theory for the nonlinear system allows an improved control effect for movements in "sliding mode" when compared with conventional control. The fuzzy control theory is also introduced, weakening output chattering caused by the sliding mode control switchover while producing high output stability. Matlab mathematical simulation and practical test verification indicate the speed control method as effective in obtaining accurate control results, thus inferring strong practical significance for engineering applications.
\end{abstract}

\section{Introduction}

Oceans cover $71 \%$ of earth's surface and feature rich biological resources with vast mineral storage. Marine scientific research related to development of marine equipment and related test devices are receiving significant attention recently as resources are further evaluated for use. The underwater vehicle provides a new platform type for carried devices that incorporate the motion of the underwater craft. Underwater vehicles accommodate sensors and operation tools and utilize computers for underwater motion testing and for transferring collected data remotely through the optics network. Precise speed control of the underwater vehicles then is key to the underwater scientific research.

Commonly used speed servo-driven methods include motor-driven and hydraulic driven winches. The motordriven winch operates with high precision and simple speed alterations yet exhibits inefficient power output, load capacity, and sealing problems in the underwater environment. The hydraulic winch, employed in this study, features higher efficiency, superior load capacity, stronger driving power, and convenient speed adjustment. Therefore, in this study we use hydraulic winch as underwater vehicle driving equipment.

Advanced control theory such as neural network, fuzzy control, and predictive control have been widely applied in the hydroserve speed control field [1]. Complexity of modern hydraulic systems due to nonlinearity, large hysteresis, timevarying parameter, and load characteristics does not allow traditional PID control to consistently meet control requirements. Newton analyzed the difference of control theory and control effects between neural network control algorithm with the traditional PID control algorithm in motor and valve control cylinder valve-controlled system [2]. Zibin et al. focused on uncertainties and designed an adaptive backstepping neural network approaching control algorithm [3]. Azimian et al. analyzed characteristics of the electrohydraulic servomotor control and designed a neural network controller currently employed in applications [4]. Istif designed two controller types: the first is a neural network predictive controller utilizing the neural network forecasting model to predict system output and the other is a nonlinear autoregressive moving average controller converting the nonlinear system into a linear dynamic system. Characteristics of each 


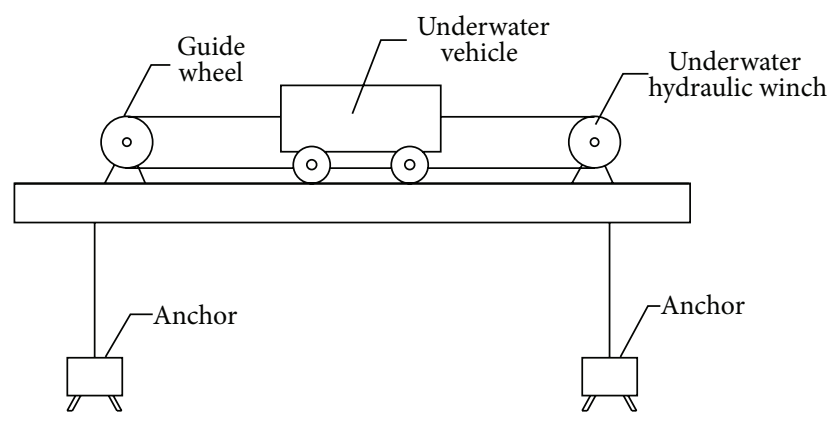

FIGURE 1: Schematic diagram of underwater vehicle propelled by hydraulic winch.

controller are analyzed through testing in the electrohydraulic servovalve control cylinder system [5].

Sliding mode control with parameter adaptability and showing good robustness for nonlinear control system has become increasingly applicable to electrohydraulic servosystems control. Mohseni et al. first introduced sliding mode control theory as applied to hydraulic cylinder servocontrol [6]. Perron et al. proposed a novel sliding mode control method for hydraulic speed control [7]. Loukianov et al., recognizing the electrohydraulic system as a typical affine nonlinear system utilizing a state feedback linear method, achieved precise control of the electrohydraulic servosystem [8]. Inherent shortcomings of the traditional sliding mode controller remain, however, restricting further development in the field of electrohydraulic servocontrol; thus application of advanced control theory to sliding mode control theory is a critical research direction for modern hydraulic control.

In this study, research was first focused on underwater vehicle control system modeling analysis. Characteristics of the hydraulic system and flexibility of the closed traction system's impact on the entire control system were examined. Sliding mode control based on reaching law was chosen as the control algorithm to control low stiffness and variable load of the system, while fuzzy control theory was applied to reduce chattering impact on the output implementation structure. The proposed underwater control method was based on fuzzy reaching law. The controlled object mathematical model was then built and digital simulation of the control method completed to verify the control algorithm and optimize parameters for practical testing.

\section{Modeling of Underwater Vehicle Control System}

Figure 1 displays a schematic diagram of the underwater vehicle propelled by underwater hydraulic winch. The underwater vehicle is $5 \mathrm{~m}$ long, $1.2 \mathrm{~m}$ wide, $13.5 \mathrm{~m}$ high, and $3000 \mathrm{~kg}$, installed on the guide rail of the platform deck surface. The underwater hydraulic winch and guide wheel are located on each end of the $50 \mathrm{~m}$ long rail and the winch drum is a monolayer cylinder. Two traction ropes are fixed and wound on the winch drum forming the closed flexible traction structure. The upper rope end is fixed on one end of the hydraulic vehicle and the lower end fixed on the other end of the hydraulic vehicle along the guide rail across the wheel. Hydraulic vehicle traction may be achieved through the retractable rope when the hydraulic winch rotates. The hydraulic winch may then drive the underwater vehicle along the guide rail when the self-submersible platform is settled on the setting depth through flexible tension-leg.

The underwater vehicle must be controlled to accelerate smoothly from start to the setting test speed and speed stability maintained with less than $10 \%$ fluctuations for accurate motion simulations at each stage. Following completion of the related test, the speed of the underwater vehicle should gradually decelerate to zero; thus speed control system then must operate with refined precision, response, and stability. As shown in Figure 1, closed flexible traction structure allows the hydraulic winch to propel the underwater vehicle. Accurate speed control is challenged as a result of rope flexibility reducing stiffness of the traction system and change of water resistance while the underwater vehicle is moving, creating variability for the external load system.

As it is described in Figure 2, the underwater vehicle speed controller calculates the value of opening degree of valve based on the difference between the measured value and the given value of the underwater vehicle. The underwater vehicle moves with closed flexible traction structure as it is driven by the hydraulic winch and speed is determined by the open degree of the valve. It experienced variable disturbance from water resistance and flexibility of the rope during the test due to influence of water resistance and rope flexibility.

2.1. Modeling of Closed Flexible Traction Structure. The hydraulic winch drives the underwater vehicle through the closed flexible traction structure and the guide wheel attachment (Figure 3). A tension force $F$ is applied to the rope by the hydraulic cylinder through the guide wheel to avoid speed control errors caused by fluttering of the rope. The rope is divided into three sections $\left(L_{1}, L_{2}, L_{3}\right)$, according to location of the guide wheel, the underwater vehicle, and the hydraulic winch; hence, the stresses of three parts are defined as $F_{1}, F_{2}$, and $F_{3}$. The vehicle is subjected to three forces when propelled by the hydraulic winch, namely, the forward pulling force $F_{1}$, backward pushing force $F_{3}$, and resistance $f$. The guide wheel force is the sum of driving force $F_{2}$ and resistance $F_{1}$, while the hydraulic winch is subject to resistance $F_{2}$ and pulling force $F_{3}$.

The dynamics formula of the underwater vehicle may be obtained through the analysis:

$$
F_{1}-F_{3}-f=M \frac{d v}{d t}+B_{2} v_{L}
$$

where $F_{1}$ is the tension force of $L_{1}, F_{3}$ is the tension force of $L_{3}, f$ is water resistance force applied on the vehicle, $M$ is the mass of the underwater vehicle, $B_{2}$ is the friction coefficient between vehicle wheels and guide rail, and $v_{L}$ is motion speed of the underwater vehicle.

Force analysis for steel rope is critically important for determining underwater vehicle speed control utilizing the closed flexible traction system. 


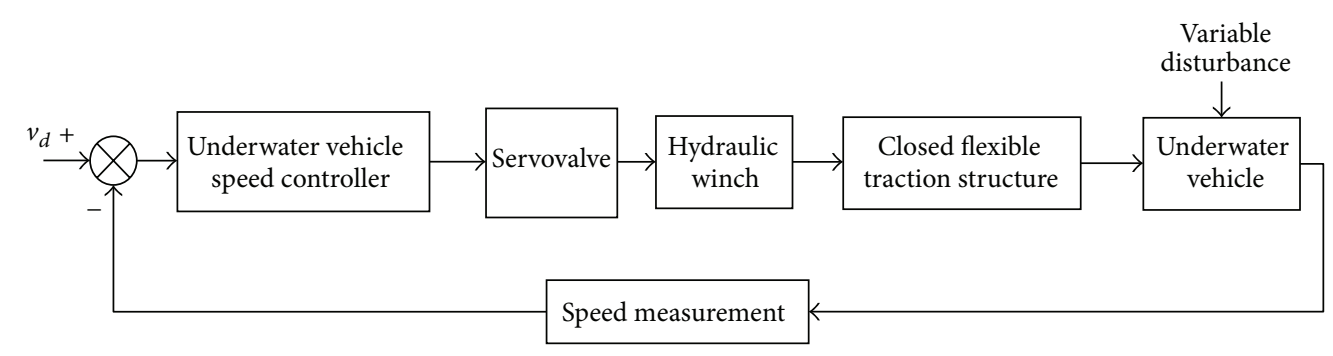

FIgURE 2: Speed control of the underwater vehicle.
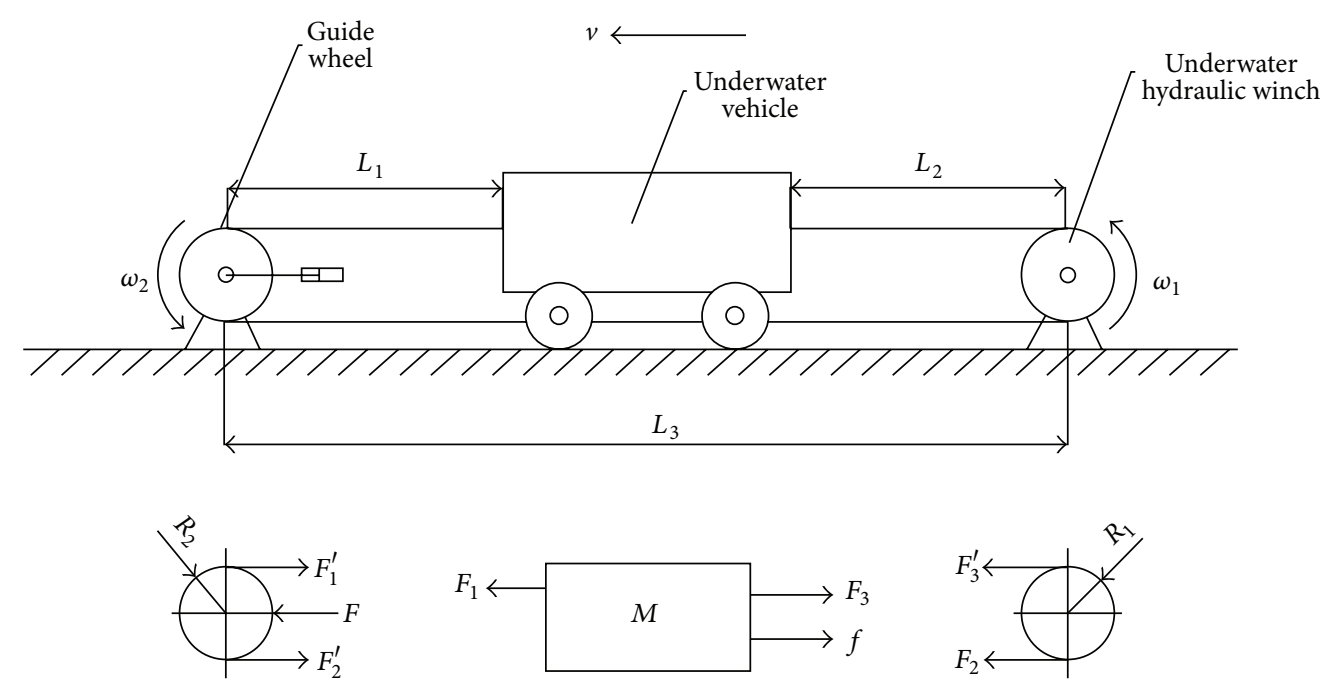

FIGURE 3: Schematic diagram of the underwater vehicle drafted by hydraulic winch.

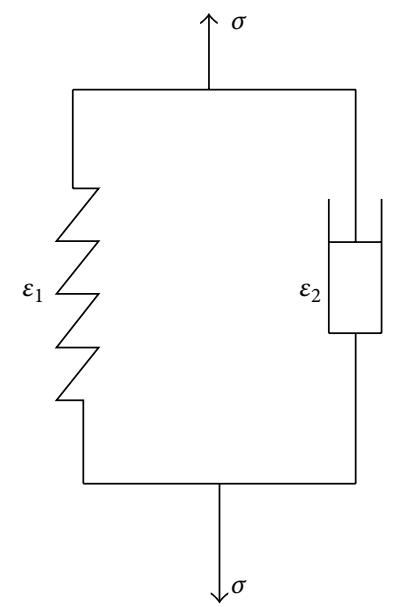

Figure 4: Kelvin-Voigt model.

Traditional static design assumes steel rope is a rigid body, yet the actual rope is twisted by multiple steel cores wired together, presenting more complex mechanical properties referred to as viscoelasticity when subjected to tension [9]. The Kelvin-Voigt model is employed in this study as a mechanical model of the rope (Figure 4). The model is also referred to as a nonrelaxation model as it is made with parallel springs and dampers and considers both elasticity and viciousness of the rope presented during stretching [10].

The simplified diagram of the model is a result of substituting the rope model in the closed flexible traction structure (Figure 5).

Elongation of each rope segment, referred to as static status, in the guide wheel tension force $F$ is, respectively, denoted as $x_{10}, x_{20}$, and $x_{30}$.

The forces of each segment are as follows:

$$
\begin{aligned}
& F_{10}=k_{1} x_{10}, \\
& F_{20}=k_{2} x_{20}, \\
& F_{30}=k_{3} x_{30} .
\end{aligned}
$$

When the hydraulic winch propels the vehicle, the forces for each segment are

$$
\begin{aligned}
& F_{1}=F_{10}+\Delta F_{1}=k_{1}\left(x_{10}+\Delta x_{1}\right)+c_{1} \cdot \Delta \dot{x}_{1}, \\
& F_{2}=F_{20}+\Delta F_{2}=k_{2}\left(x_{20}+\Delta x_{2}\right)+c_{2} \cdot \Delta \dot{x}_{2}, \\
& F_{3}=F_{30}+\Delta F_{3}=k_{3}\left(x_{30}+\Delta x_{3}\right)+c_{3} \cdot \Delta \dot{x}_{3},
\end{aligned}
$$




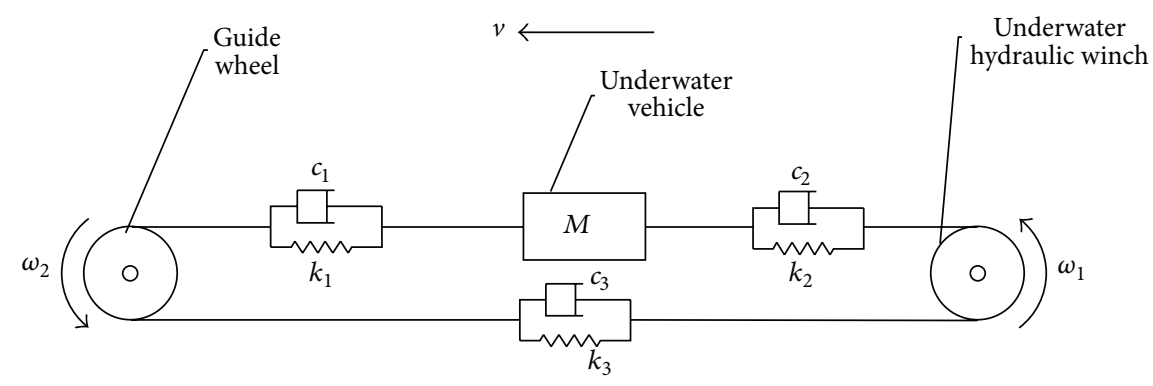

FIGURE 5: Simplified diagram of underwater vehicle propelled by hydraulic winch, where $\omega_{1}$ is the angular speed of hydraulic winch rotation, $R$ is the radium of drum, $\omega_{2}$ is the guide wheel rotational speed, $R$ represents radium, $k_{1}$ and $c_{1}$ are the elasticity and viciousness of $L_{1}, k_{2}$ and $c_{2}$ are the elasticity and viciousness of $L_{2}$, and $k_{3}$ and $c_{3}$ are the elasticity and viciousness of $L_{3}$.

where $\Delta x_{1}, \Delta x_{2}$, and $\Delta x_{3}$ are the elongations of each segment of rope while the vehicle moves and $x_{L}$ is the distance of vehicle. Consider

$$
\begin{aligned}
& \Delta x_{1}=\int \omega_{2} d t \cdot R-x_{L}, \\
& \Delta x_{2}=\int \omega_{1} d t \cdot R-\int \omega_{2} d t \cdot R, \\
& \Delta x_{3}=x_{L}-\int \omega_{1} d t \cdot R .
\end{aligned}
$$
into

Substitute above equations into (1) and let it be simplified

$$
\begin{aligned}
F_{1}-F_{3}= & k_{1}\left(x_{10}+\Delta x_{1}\right)+c_{1} \cdot \Delta \dot{x}_{1}-k_{3}\left(x_{30}+\Delta x_{3}\right) \\
& -c_{3} \cdot \Delta x_{3} \\
= & k_{1} \cdot \Delta x_{1}+c_{1} \cdot \Delta \dot{x}_{1}-k_{3} \cdot \Delta x_{3}-c_{3} \cdot \Delta \dot{x}_{3} \\
= & M \cdot \dot{v}_{L},
\end{aligned}
$$

where set $L_{1}, L_{3}$ are equally forced under pretension $F_{10}=$ $F_{30}$.

Equation (5) can be written as:

$$
\begin{aligned}
k_{1} & \cdot \Delta x_{1}(s)+c_{1} \cdot \Delta x_{1}(s) s-k_{3} \cdot \Delta x_{3}(s)-c_{3} \cdot \Delta x_{3}(s) s \\
& =M \cdot v_{L}(s) s .
\end{aligned}
$$

Substituting (4) in (6) results in:

$$
\begin{aligned}
k_{1} \cdot\left(\omega_{2}(s) \cdot R-v_{L}(s)\right)+c_{1} \cdot\left(\omega_{2}(s) s \cdot R-v_{L}(s) s\right) \\
-k_{3} \cdot\left(v_{L}(s)-\omega_{1}(s) \cdot R\right)-c_{3} \\
\cdot\left(v_{L}(s) s-\omega_{1}(s) s \cdot R\right)=M \cdot v_{L}(s) s^{2} .
\end{aligned}
$$

In closed flexible structure traction, the relationship between the underwater vehicle speed and hydraulic winch speed is

$$
\frac{v_{L}(s)}{\omega(s)}=\frac{(2 c s+2 k) \cdot R}{M s^{2}+2 c s+2 k},
$$

where set steady speed, the hydraulic winch, and guide wheel have equal rotational speed, $\omega(s)=\omega_{1}(s)=\omega_{2}(s)$. Two segments share the same properties, elasticity coefficient $k=$ $k_{1}=k_{3}$, viscosity coefficient $c=c_{1}=c_{3}$, and $v_{L}$ is motion speed of the underwater vehicle.

As it can be seen from (8), the relationship between the underwater vehicle speed and hydraulic winch speed showing second-order nonlinearity differs between a closed flexible traction system and a rigidly connected traction system due to viscoelastic properties of the rope. The secondorder system, resulting from viscoelasticity of the rope, reduces stiffness of the traction system adding difficulty to underwater vehicle speed control.

2.2. Modeling of Hydraulic Winch System. A valve-controlled hydraulic winch is utilized as the driving mechanism of the underwater vehicle in this study.

Hydraulic motor dynamic mathematical model is constructed by the hydraulic valve flow equation, hydraulic motor continuity equation, and the motor torque balance equations [11].

(1) Hydraulic Valve Flow. Assumed valve is in ideal condition. Hydraulic valve flow equation is a typical nonlinear equation:

$$
Q_{L}=c_{d} \omega x_{v} \sqrt{\frac{1}{\rho}\left(p_{s}-p_{L} \operatorname{sgn}\left(x_{v}\right)\right)},
$$

where $Q_{L}$ is load flow, $c_{d}$ is the valve orifice flow coefficient, $\omega$ is the valve area gradient, $p_{s}$ is oil pressure of hydraulic pump supply, $p_{L}$ is the load pressure, and $\rho$ is hydraulic oil density.

(2) Hydraulic Motor Continuity Equation. The following assumptions are made in the analysis of the hydraulic motor continuity equation: all pipes are short and thick; pipe friction loss, pipeline fluid dynamic impact, and quality may be negligible.

Provided $Q_{1}$ is the quantity flow into oil chamber of the hydraulic motor and $Q_{2}$ is the quantity flow from oil chamber of the hydraulic motor, there is

$$
\begin{aligned}
& Q_{1}=C_{\mathrm{im}}\left(p_{1}-p_{2}\right)+C_{\mathrm{em}} p_{1}+D_{\mathrm{m}} \frac{d \theta_{\mathrm{m}}}{d t}+\frac{V_{1}}{\beta_{e}} \frac{d p_{1}}{d t} \\
& Q_{1}=C_{\mathrm{im}}\left(p_{1}-p_{2}\right)-C_{\mathrm{em}} p_{2}+D_{\mathrm{m}} \frac{d \theta_{\mathrm{m}}}{d t}-\frac{V_{2}}{\beta_{e}} \frac{d p_{2}}{d t} .
\end{aligned}
$$


Working volume of the hydraulic motor may be, respectively, described as

$$
\begin{aligned}
& V_{1}=V_{01}+D_{\mathrm{m}} \theta_{\mathrm{m}}, \\
& V_{2}=V_{02}+D_{\mathrm{m}} \theta_{\mathrm{m}},
\end{aligned}
$$

where $V_{01}$ and $V_{02}$ were initial volume of motor oil chamber and back oil chamber.

Since the leakage and compression resistance of the hydraulic motor, quantity flow into oil chamber $Q_{1}$, and quantity flow from oil chamber $Q_{2}$ are different, in order to simplify the analysis, define load flow $Q_{L}$ as

$$
\begin{aligned}
Q_{L}= & \frac{Q_{1}+Q_{2}}{2} \\
= & D_{\mathrm{m}} \frac{d \theta_{\mathrm{m}}}{d t}+\left(C_{\mathrm{im}}+\frac{1}{2} C_{\mathrm{em}}\right) p_{L} \\
& +\frac{1}{2}\left(\frac{V_{1}}{\beta_{e}} \frac{d p_{1}}{d t}-\frac{V_{2}}{\beta_{e}} \frac{d p_{2}}{d t}\right) \\
& +\frac{D_{\mathrm{m}} \theta_{\mathrm{m}}}{2 \beta_{e}}\left(\frac{d p_{1}}{d t}+\frac{d p_{2}}{d t}\right),
\end{aligned}
$$

where $D_{\mathrm{m}}$ is the theoretical flow hydraulic motor; $\theta_{\mathrm{m}}$ is the angle of the hydraulic motor shaft; $C_{\mathrm{im}}$ is the bypass leakage coefficient for internal hydraulic motor; $C_{\mathrm{em}}$ is the leakage coefficient for external hydraulic motors; $V_{1}$ is oil chamber volume of hydraulic motor; and $V_{2}$ is the back oil chamber volume of hydraulic motor.

Assume the inertial volume of oil chamber and back oil chamber as

$$
V_{01}=V_{02}=V_{0}=\frac{1}{2} V_{\mathrm{m}}
$$

where $V_{\mathrm{m}}$ is the total volume of hydraulic valve chamber, motor chamber, and connecting pipes. Because $D_{\mathrm{m}} \theta_{\mathrm{m}} \ll V_{0}$, $p_{s}=p_{1}+p_{2}=C$ (constant), $p_{L}=p_{1}-p_{2}$, but also $d p_{1} / d t+d p_{2} / d t=0$, formula (12) may be written as

$$
Q_{L}=D_{\mathrm{m}} \frac{d \theta_{\mathrm{m}}}{d t}+C_{\mathrm{tm}} p_{L}+\frac{V_{\mathrm{m}}}{4 \beta_{e}} \frac{d p_{L}}{d t}
$$

where $C_{\mathrm{tm}}$ is the total leakage coefficient of hydraulic motor $C_{\mathrm{tm}}=C_{\mathrm{im}}+(1 / 2) C_{\mathrm{em}}$ and $\beta_{e}$ is elasticity modulus for the hydraulic oil.

(3) Motor Torque Balance Equations. Dynamic characteristics of the hydraulic motor power components are affected by load characteristics. Load force typically includes inertial forces, viscous damping force, elastic force, and arbitrary external load force. Disregarding the effects of nonlinear loads and oil quality of friction, according to Newton's Law, hydraulic motor torque equilibrium equation may be drawn as

$$
T_{s}=p_{L} D_{\mathrm{m}}=J_{\mathrm{m}} \frac{d^{2} \theta_{\mathrm{m}}}{d t^{2}}+B_{\mathrm{m}} \frac{d \theta_{\mathrm{m}}}{d t}+G \theta_{\mathrm{m}}+T_{L},
$$

where $T_{s}$ is the theoretical torque generated by hydraulic motor; $J_{\mathrm{m}}$ is the total inertia of the hydraulic motor and load;

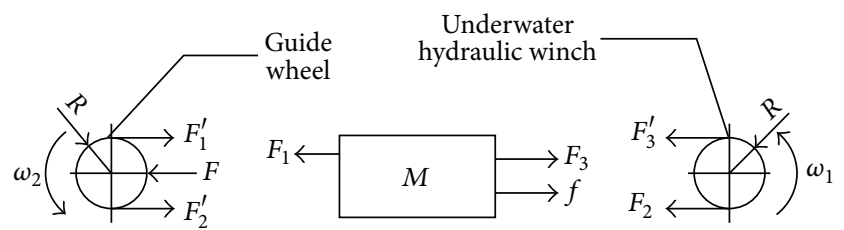

FIGURE 6: The force analysis of the closed flexible traction structure.

$B_{\mathrm{m}}$ is the viscous damping coefficient of load and hydraulic motor; $G$ is the load torsion spring stiffness; and $T_{L}$ is the external load torque acting on the motor shaft.

Equations (9), (14) and (15) can be written as:

$$
\begin{aligned}
& Q_{L}=K_{q} x_{v}-K_{c} p_{L}, \\
& Q_{L}=D_{\mathrm{m}} s \theta_{\mathrm{m}}+C_{\mathrm{tm}} p_{L}+\frac{V_{t}}{4 \beta_{e}} s p_{L}, \\
& T_{s}=p_{L} D_{\mathrm{m}}=J_{t} s^{2} \theta_{\mathrm{m}}+B_{\mathrm{m}} s \theta_{\mathrm{m}}+G \theta_{\mathrm{m}}+T_{L} .
\end{aligned}
$$

Eliminating the middle term, the transform function of the valve opening degree and vehicle speed can be obtained [12] as follows:

$$
\dot{\theta_{\mathrm{m}}}=\frac{\left(K_{q} / D_{\mathrm{m}}\right) x_{v}-\left(1 / D_{\mathrm{m}}^{2}\right)\left(K_{c e}+\left(V_{\mathrm{m}} / 4 \beta_{e}\right) s\right) \cdot T_{L}}{s^{2} / \omega_{h}^{2}+\left(2 \zeta_{h} / \omega_{h}\right) s+1},
$$

where $\omega_{h}=\sqrt{K_{h} / J}=\sqrt{4 \beta_{e} D_{\mathrm{m}}^{2} / V_{\mathrm{m}} J}$ is equivalent hydraulic natural frequency; $\zeta_{h}=\left(K_{c e} / D_{\mathrm{m}}\right) \sqrt{\beta_{e} J / V_{\mathrm{m}}}+$ $\left(B_{\mathrm{m}} / 4 D_{\mathrm{m}}\right) \sqrt{V_{\mathrm{m}} / \beta_{e} J}$ is damping ratio of hydraulic valvecontrolled motor; and $K_{c e}=K_{c}+C_{\mathrm{im}}+(1 / 2) C_{\mathrm{em}}$ is coefficient of flow-pressure.

External load is the key factor of the underwater vehicle's speed control from the analysis above.

2.3. Modeling of External Load. The force analysis of the closed flexible traction structure is described as shown in Figure 6.

When underwater hydraulic winch drives the vehicle to move, the winch is a driving wheel and the guide wheel is a drive wheel. The force of guide wheel is the sum of driving force $F_{2}$ and resistance $F_{1}$, while the rotational speed of guide wheel is $\omega_{2}$. The torque equilibrium equation of guide wheel may be obtained as

$$
\left(F_{2}-F_{1}\right) \cdot R=J_{2} \frac{d \omega_{2}}{d t}+B_{1} \omega_{2},
$$

where $F_{1}$ is the tension force of $L_{1}, F_{2}$ is the tension force of $L_{2}, J_{2}$ is the torque of guide wheel, $B_{2}$ is the friction coefficient between vehicle wheels and guide rail, and $\omega_{2}$ is rotational speed of the guide wheel.

The dynamics formula of the underwater vehicle may be obtained utilizing Newton's Law:

$$
F_{1}-F_{3}=M \frac{d v_{L}}{d t}+B_{2} v_{L}+f,
$$


where $F_{1}$ is the tension force of $L_{1}, F_{3}$ is the tension force of $L_{3}, f$ is the water resistance force applied on the vehicle, $M$ is the mass of the underwater vehicle, $B_{2}$ is the friction coefficient between vehicle wheels and the guide rail, and $v_{L}$ is motion speed of the underwater vehicle.

The hydraulic winch is a driving wheel and the torque equilibrium equation may be obtained as

$$
T_{L}=\left(F_{2}-F_{3}\right) \cdot \frac{R}{n},
$$

where $n$ is speed ratio of the hydraulic winch and $R$ is the radium.

Substituting (18) and (19) in (20), the torque equilibrium equation of hydraulic winch may be written as

$$
\begin{aligned}
T_{L} & =\left[\left(F_{2}-F_{1}\right)+\left(F_{1}-F_{3}\right)\right] \cdot \frac{R}{n} \\
& =\left(\frac{J_{2}\left(d \omega_{2} / d t\right)+B_{1} \omega_{2}}{R}+M \frac{d v_{L}}{d t}+B_{2} v_{L}+f\right)
\end{aligned}
$$

$$
\begin{aligned}
& \frac{R}{n} \\
= & \frac{J_{2}}{n} \frac{d \omega_{2}}{d t}+\frac{B_{1} \omega_{2}}{n}+\left(M \frac{d v_{L}}{d t}+B_{2} v_{L}+f\right) \cdot \frac{R}{n} .
\end{aligned}
$$

Equation (21) can be written as:

$$
\begin{aligned}
& T_{L}(s)=\left[J_{2} \cdot \omega_{2}(s) s+B_{1} \cdot \omega_{2}(s)+M R \cdot v_{L}(s) s\right. \\
& \left.\quad+B_{2} R \cdot v_{L}(s)+R \cdot f(s)\right] \cdot \frac{1}{n} .
\end{aligned}
$$

The relationship between the underwater vehicle speed and hydraulic winch speed from the analysis above is

$$
\frac{v_{L}(s)}{\omega(s)}=\frac{(2 c s+2 k) \cdot R}{M s^{2}+2 c s+2 k}
$$

and may be written as

$$
\frac{\omega(s)}{v_{L}(s)}=\frac{M s^{2}+2 c s+2 k}{(2 c s+2 k) \cdot R} .
$$

Substituting (24) in (22), the torque equilibrium equation of hydraulic may be obtained as

$$
\begin{aligned}
& T_{L}(s)=\left[\left(J_{2} s+B_{1}\right) \cdot \frac{M s^{2}+2 c s+2 k}{(2 c s+2 k) \cdot R}+\left(M R s+B_{2} R\right)\right] \cdot \frac{v_{L}(s)}{n}+\frac{R}{n} \cdot f(s) \\
& =\frac{M J_{2} s^{3}+\left(M B_{1}+2 c J_{2}+2 c M R^{2}\right) s^{2}+\left(2 B_{1} c+2 k J_{2}+2 c B_{2} R^{2}+2 k M R^{2}\right) s+\left(2 k B_{1}+2 k B_{2} R^{2}\right) s+\left(2 k B_{1}+2 k B_{2} R^{2}\right)}{(2 c s+2 k) \cdot n R} \\
& \quad \cdot v_{L}(s)+\frac{R}{n} \cdot f(s),
\end{aligned}
$$

where $T_{L}(s)$ is the torque equilibrium equation of hydraulic winch, $v_{L}(s)$ is motion speed of the underwater vehicle, and $f(s)$ is the water resistance force applied on the vehicle.

The software application, "Gambit," was applied to calculate water resistance force on the vehicle. Analyzing the shape of the underwater vehicle, drag force coefficients may be derived as

$$
C_{d}=0.275 .
$$

Water resistance force applied on the vehicle may be written as

$$
f=\frac{1}{2} C_{d} \rho A v_{L}^{2},
$$

where $C_{d}$ represents drag force coefficients of the underwater vehicle, $\rho$ is density of water, $A$ is horizontal projection area of underwater vehicle, and $v_{L}$ is motion speed of the underwater vehicle.

The hydraulic winch external load torque in the closed flexible traction driving system (25) is affected by both the underwater vehicle speed and water resistance. The speed of the vehicle is variable during the test and the value of water resistance is related to the speed; thus the external load torque of hydraulic winch is variable.

2.4. Modeling of the Underwater Vehicle Speed Control System. Combining (17), (24), and (25), the transfer function diagram of the underwater vehicle speed control system may be obtained (Figure 7).

Compared with the conventional hydraulic winch speed servocontrol system, since steel rope is introduced as traction material, the viscoelastic properties of the steel rope present second-order system characteristics on the forward channel of the speed control system, reducing system stiffness and challenging stability for underwater vehicle speed control. The closed flexible structure and underwater environment result in certain relevance between traction load characteristics and underwater vehicle speed, while the underwater vehicle constantly changes speed through entire experiment; the load characteristic of hydraulic system is also variable and 


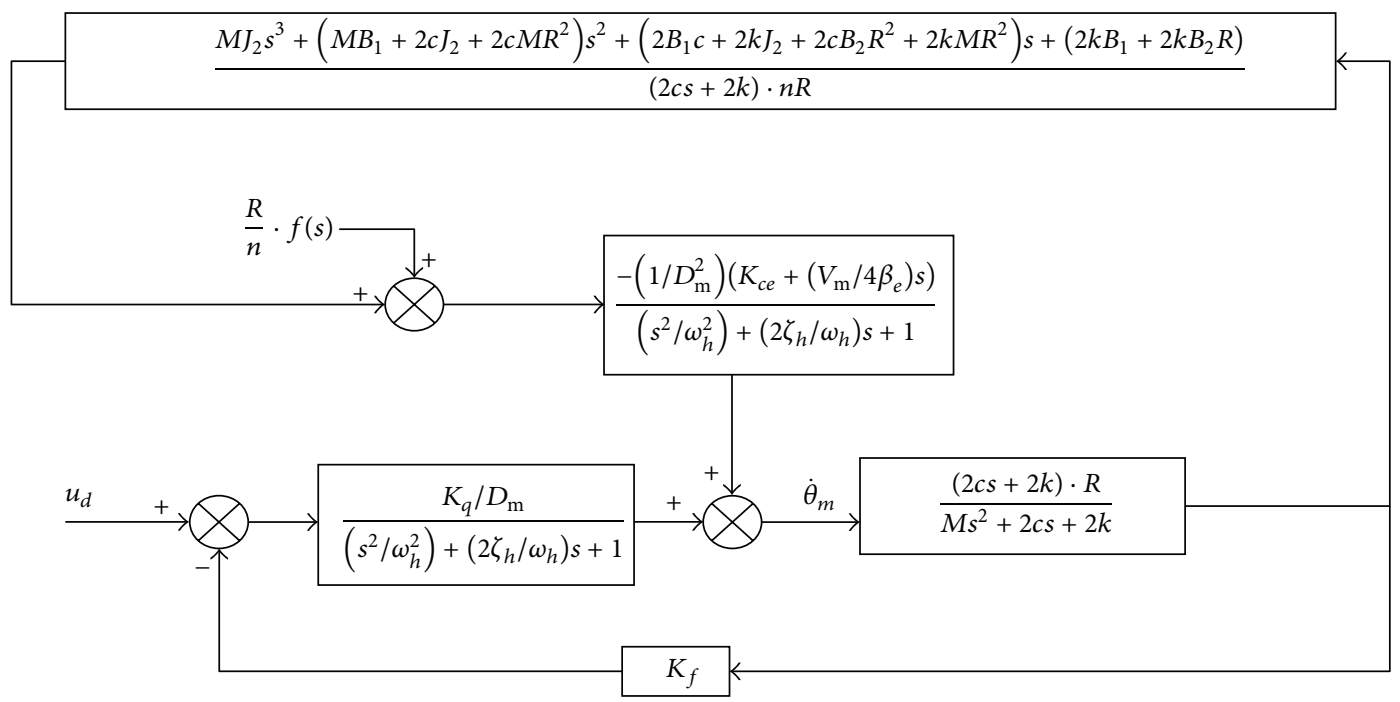

FIGURE 7: The transfer function diagram of the underwater vehicle speed control system.

consequently brings difficulty on accuracy of the underwater vehicle speed control.

\section{Research on Fuzzy Sliding Mode Control}

The speed control system of the underwater vehicle presents low rigidity, time-varying, and nonlinear parameters, according to the above analysis. Reliability and responsiveness for stability and accuracy of the control system then must be considered when choosing a control algorithm.

Sliding mode variable structural control theory is selected as theoretical support of the underwater vehicle speed control method in this study. Sliding mode variable structure control is essentially a special type of nonlinear control, since the discontinuity of control output. Differing from other control methods, the sliding mode control strategy features a variable system structure that evolves according to the current system state, forcing the system to move along the designed "sliding mode" state track. Sliding mode design is irrelevant to object parameters; thus it is highly responsive and insensitive to parameter variables and disturbance and shows good robustness [13].

3.1. Sliding Mode Control Based on Reaching Law. Sliding mode system motion consists of two states: first, in the normal motion state, the state space trajectory occurs outside the switching surface or across the switching surface by limited time. Second, in the sliding motion state, the system moves near the switching surface in the sliding mode. Sliding control requires high motion quality throughout the entire control process of both the normal state and the sliding mode state.

According to the sliding mode variable structure principle, the sliding reachability condition is only guaranteed when the state space reaches the switching surface from any points in limited time, but approaching trajectory is not restricted; the reaching law method can improve the dynamic quality of approaching movement. The secondorder electrohydraulic system may be applied as an example to derive the sliding mode control algorithm based on exponential reaching law [14].

Consider a second-order electrohydraulic system state equation

$$
\dot{x}=A x+B u+d,
$$

where $x=\left(\begin{array}{l}x_{1} \\ x_{2}\end{array}\right)$ is system state variable, $A=\left(\begin{array}{ll}a_{11} & a_{12} \\ a_{21} & a_{22}\end{array}\right)$ and $B=\left(\begin{array}{l}b_{1} \\ b_{2}\end{array}\right)$ are system state parameters, and $d$ is disturbance.

Then $\ddot{x}=a_{21} x_{1}+a_{22} x_{2}+b_{2} u+d_{2}$.

Setting a given value $r$, the error signal is

$$
\begin{aligned}
& e=r-x_{1}, \\
& \dot{e}=\dot{r}-x_{2} .
\end{aligned}
$$

Select the sliding mode control switching function as

$$
S=C E=c e+\dot{e},
$$

where the value of the parameter $c$ should satisfy Hurwitz conditions.

The derivation of the above equation may be obtained as

$$
\begin{aligned}
\dot{S} & =C \dot{E}=c \dot{e}+\ddot{e}=c\left(\dot{r}-x_{2}\right)+\left(\ddot{r}-\dot{x}_{2}\right) \\
& =c\left(\dot{r}-x_{2}\right)+\left(\ddot{r}-a_{21} x_{1}-a_{22} x_{2}-b_{2} u-d_{2}\right) \\
& =\text { rlaw. }
\end{aligned}
$$

Variable structure control law for second-order state space model is

$$
u=\frac{1}{b_{2}}\left[\ddot{r}+c\left(\dot{r}-x_{2}\right)-a_{21} x_{1}-a_{22} x_{2}-d_{2}-r l a w\right] .
$$

As deducible from above, the conventional sliding mode control's approaching movement characteristics have not 


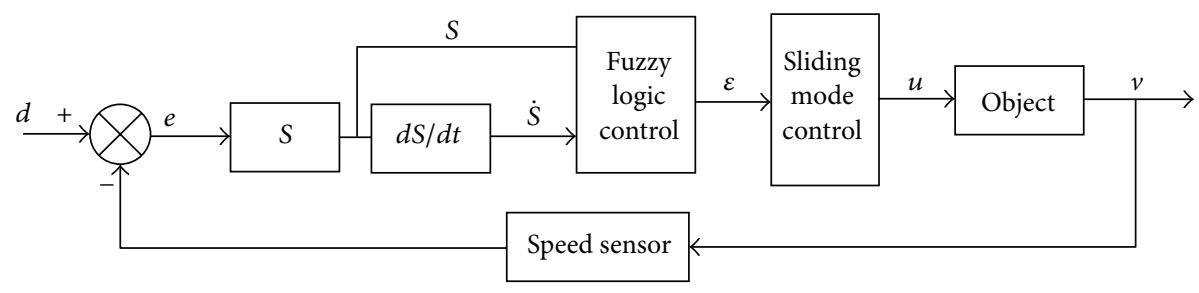

FIGURE 8: Sliding mode based on fuzzy reaching law control schematics.

been restricted; thus adopting reaching law is an effective method for improving motion characteristics of the approaching movement.

Here adopted exponential reaching law [15] is

$$
\text { rlaw }=-\varepsilon \operatorname{sgn}(s)-k s, \quad \varepsilon>0, k>0 .
$$

There is

$$
\begin{aligned}
u= & \frac{1}{b_{2}}\left[\ddot{r}+c\left(\dot{r}-x_{2}\right)-a_{21} x_{1}-a_{22} x_{2}-d_{2}\right. \\
& +\varepsilon \operatorname{sgn}(s)+k s] .
\end{aligned}
$$

Since disturbance $d_{2}$ is unknown, the above control law cannot be achieved.

Set $d_{L} \leq d_{2}(t) \leq d_{U}$; this requires interference sector to design control law:

$$
\begin{aligned}
u= & \frac{1}{b_{2}}\left[\ddot{r}+c\left(\dot{r}-x_{2}\right)-a_{21} x_{1}-a_{22} x_{2}-d_{c}+\varepsilon \operatorname{sgn}(s)\right. \\
& +k s]
\end{aligned}
$$

where $d_{c}=\left(d_{U}+d_{L}\right) / 2-\left(\left(d_{U}-d_{L}\right) / 2\right) \operatorname{sgn}(s)$.

Conditions existing to satisfy sliding mode include the following:

(1) When $S>0, \dot{S}=-\varepsilon-\operatorname{sgn}(s)+d_{c}-d$, for $\dot{S}<0$, made $d_{c}=d_{U}$.

(2) When $S<0, \dot{S}=-\varepsilon-\operatorname{sgn}(s)+d_{c}-d$, for $\dot{S}<0$, made $d_{c}=d_{L}$.

Sliding mode control, from the above analysis, based on exponential reaching law, features superior response and stability; however, because of the switching function $\varepsilon \operatorname{sgn}(s)$ introduction, output characteristics vary from conventional control. $\varepsilon \operatorname{sgn}(s)$ increases robustness of the control system while increasing the value of $\varepsilon$ and the time of system state move into the sliding mode can be reduced while $|S|<1$, thereby enhancing the dynamic quality of sliding mode control; however, a larger value of $\varepsilon$ will bring more significant control output chattering, as well as larger impact on implementation structure and control objects. Reasonable selection of switch function coefficients is particularly essential for sliding mode robust control based on reaching law.

3.2. Sliding Mode Control Based on Fuzzy Reaching Law. A reaching law method based on fuzzy logic is presented in this study to solve the contradiction in values of the sliding mode control switching function coefficient. Rapid response and stability of control are met as fuzzy logic control is combined with reaching law to reduce system chattering while considering slip mode stability control [16].

Figure 8 features the fuzzy controller and sliding mode controller. Fuzzy controller is a two-dimensional structure fuzzy control with double inputs and single output, switching function $S$ and derivation $\dot{S}$ as the inputs, and is based on fuzzy rules exponential reaching law output real-time adjust parameters $\varepsilon$. Sliding mode variable structure controller then derives underwater speed control of test vehicle based on the changing value $\varepsilon$.

Exponential reaching law parameter $\varepsilon$ may be dynamically adjusted based on the relationship between $S$ and $\dot{S}$. When system status values are further from the switching surface, a greater amount of control is required to make the system move fast to switching surface; when $|S \dot{S}|$ reflects a small value, the system has moved to the nearby switching surface and, to prevent significant chattering phenomenon, control output must be reduced for the system to move smoothly to the surface.

\section{Digital Simulation and Practical Testing}

Following completion of the control algorithm design, verification and optimization of the control scheme must be conducted. The built mathematical model of the hydraulic system is utilized to realize digital simulation of the control algorithm. Practical tests then must be conducted to verify the control effect of the hydraulic system.

4.1. Model Simplification. According to design and selection of the hydraulic winch, the main nominal parameters at a given speed of the hydraulic servosystem are displayed in Table 1.

Transfer function diagram of the underwater vehicle speed control system may then be obtained (Figure 9).

Transfer function of the underwater vehicle speed control system may be written as

$$
\begin{aligned}
v_{L}(s)= & \frac{2.89 s+1.534 \times 10^{2}}{4.218 s^{2}+3.115 s+1.594 \times 10^{3}} u(s) \\
& -\frac{14.85 s^{2}+538 s+43.68}{2.2 s^{2}+1.6 s+880} v(s) \\
& -\frac{1.406 s+51.07}{625 s^{2}+4.54 \times 10^{2} s+2.4 \times 10^{5}} f(s),
\end{aligned}
$$

where $v_{L}(s)$ is motion speed of the underwater vehicle, $u(s)$ is the control input of hydraulic winch, $v(s)$ is motion speed of 
TABLE 1: The main nominal parameters of hydraulic system.

\begin{tabular}{|c|c|c|c|c|}
\hline Number & Parameter & Note & Unit & Nominal \\
\hline 1 & Drum radius & $R$ & $\mathrm{~m}$ & 0.768 \\
\hline 2 & Winch reduction ratio & $N$ & & 600 \\
\hline 3 & Flow spool gain & $K_{q}$ & & 0.003 \\
\hline 4 & Proportional valve gain & K & $\mathrm{m} / \mathrm{V}$ & $1.25 \times 10^{-3}$ \\
\hline 5 & Orifice flow coefficient & $C_{d}$ & & 0.61 \\
\hline 6 & Valve area gradient & $\Omega$ & $\mathrm{m}$ & 0.785 \\
\hline 7 & Hydraulic oil pressure & $P_{s}$ & $\mathrm{~Pa}$ & $1.5 \times 10^{7}$ \\
\hline 8 & Hydraulic oil density & $P$ & $\mathrm{~kg} / \mathrm{m}^{3}$ & 850 \\
\hline 9 & Hydraulic motor displacement & $D_{\mathrm{m}}$ & $\mathrm{m}^{3} / \mathrm{rad}$ & $1.178 \times 10^{-4}$ \\
\hline 10 & Tank volume & $V_{t}$ & $\mathrm{~m}^{3}$ & $1.47 \times 10^{-3}$ \\
\hline 11 & Bulk modulus & $\beta_{e}$ & $\mathrm{~Pa}$ & $7.0 \times 10^{8}$ \\
\hline 12 & Total flow pressure coefficient & $K_{c e}$ & $\mathrm{~m}^{5} /(\mathrm{N} \cdot \mathrm{s})$ & $1.9 \times 10^{-11}$ \\
\hline 13 & Vehicle mass & $M$ & $\mathrm{~kg}$ & 3000 \\
\hline 14 & Horizontal projection area of underwater vehicle & $A$ & $\mathrm{~m}^{2}$ & 12.99 \\
\hline
\end{tabular}

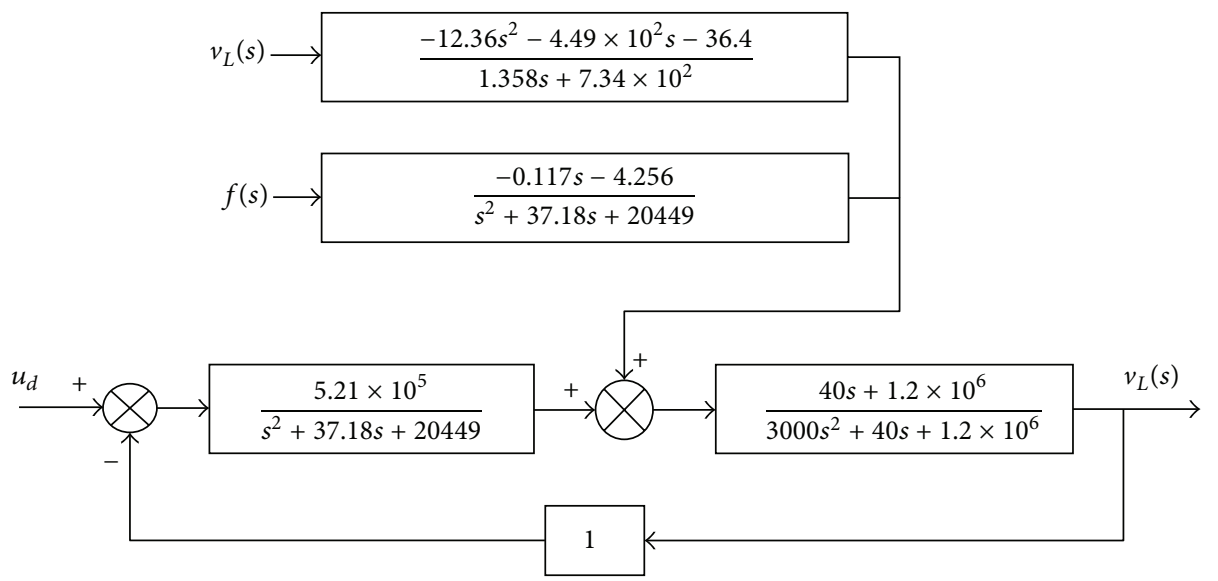

FIGURE 9: The transfer function diagram of the underwater vehicle speed control system.

the underwater vehicle on last measuring period, and $f(s)$ is water resistance force applied on the vehicle.

The function can be simplified as

$$
\begin{aligned}
& v_{L}(s) \\
& \quad=\frac{3240 u(s)-(20.59 s+16.7) v(s)-0.716 f(s)}{2.613 s^{2}+1.907 s+336.7} .
\end{aligned}
$$

The state variables of the underwater vehicle speed control system may be chosen as $x_{1}=v_{L}$ and $x_{2}=\dot{x}_{1}$; then the state equation may be obtained as

$$
\begin{aligned}
x_{1}= & v_{L}, \\
\dot{x_{1}}= & x_{2}, \\
\dot{x_{2}}= & -128.8 x_{1}-0.729 x_{2}+1239 u \\
& -(7.87 \dot{v}+6.39 v+0.27 f),
\end{aligned}
$$

where $v(s)$ is motion speed of the underwater vehicle on last measuring period and $f(s)$ is water resistance force applied on the vehicle.
Three different algorithms have been utilized in digital simulation (Figure 10) to realize the speed control system of the underwater vehicle above.

4.2. Simulation Based on PID Control Law. Figure 11 is a digital simulation diagram utilizing PID control. A speed tracking curve is depicted on the left and a control input curve of the hydraulic winch is depicted on the right. The set speed increases to $2 \mathrm{~m} / \mathrm{s}$ in $1 \mathrm{~s}$ and remains uniform. PID control law ultimately completes stable speed control of the underwater vehicle with relatively stable control input and a slightly longer stabilization time (approximately $5 \mathrm{~s}$ ).

A digital simulation diagram utilizing PID control at variable speeds is displayed in Figure 12. Sinusoidal signal is selected as set speed (max speed is $1 \mathrm{~m} / \mathrm{s}$ ) in this simulation. Control requirements experience difficulty due to a delay as the PID controller shows a less sensitive response in tracking the sinusoidal signal.

4.3. Simulation Based on Sliding Mode Control. The sliding surface is $s=15 e+\dot{e}$. 


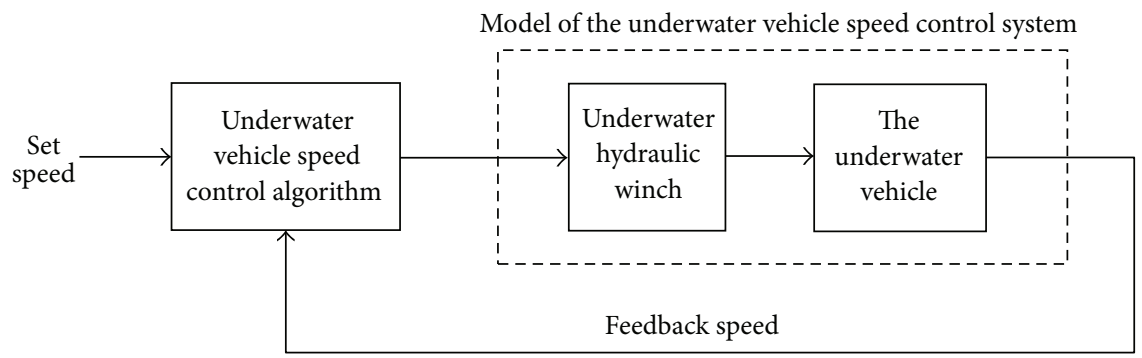

FIGURE 10: The schematic diagram of digital simulation.
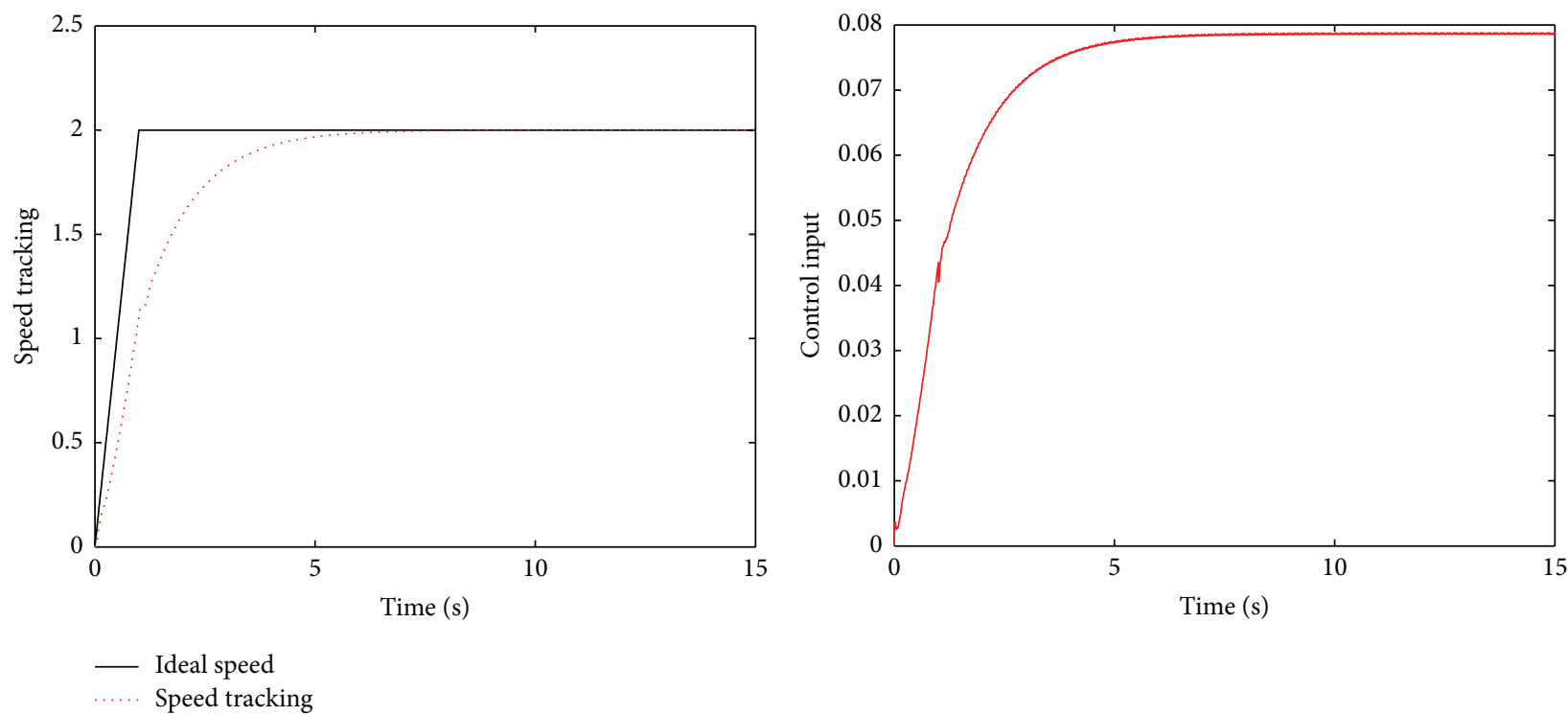

FIGURE 11: Simulation curve based on PID control law at constant speed.
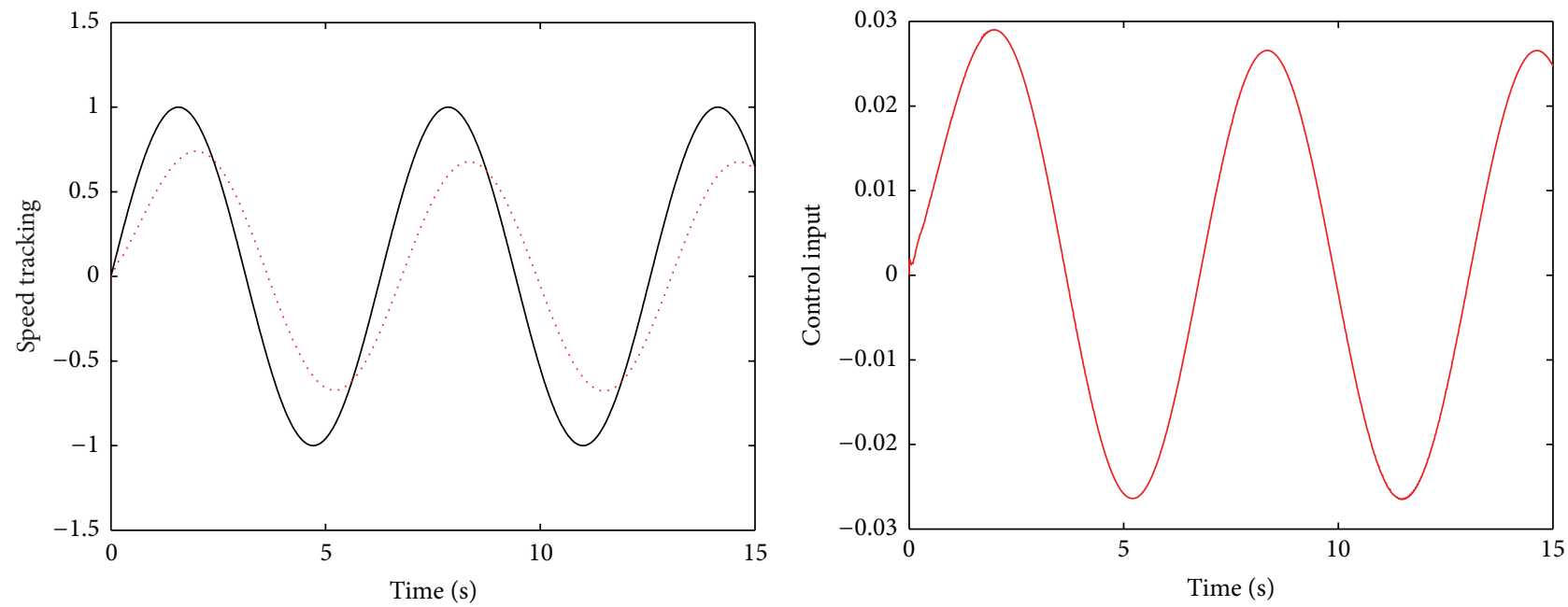

- Ideal speed Speed tracking

FIGURE 12: Simulation curve based on PID control law at variable speed. 

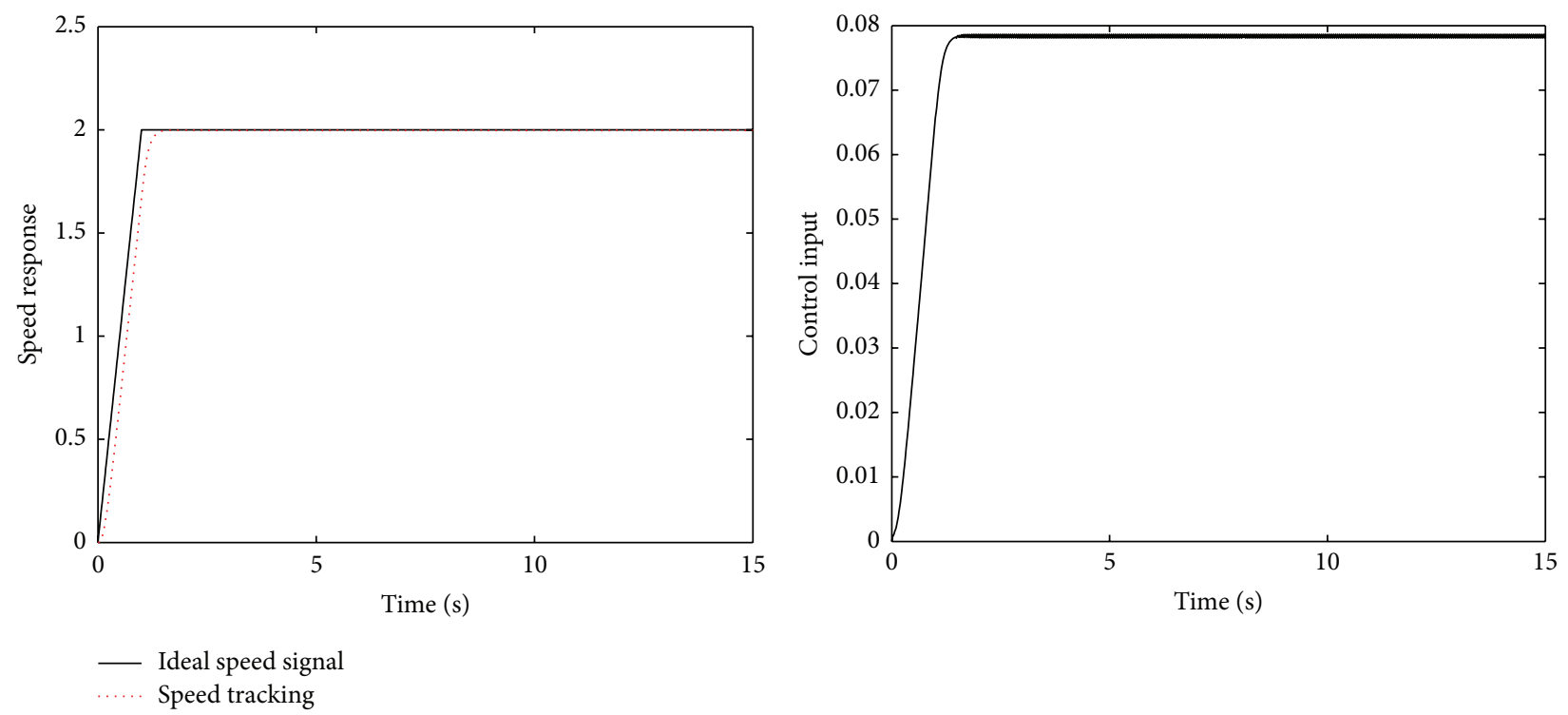

FIGURE 13: Simulation curve based on sliding mode control at constant speed.
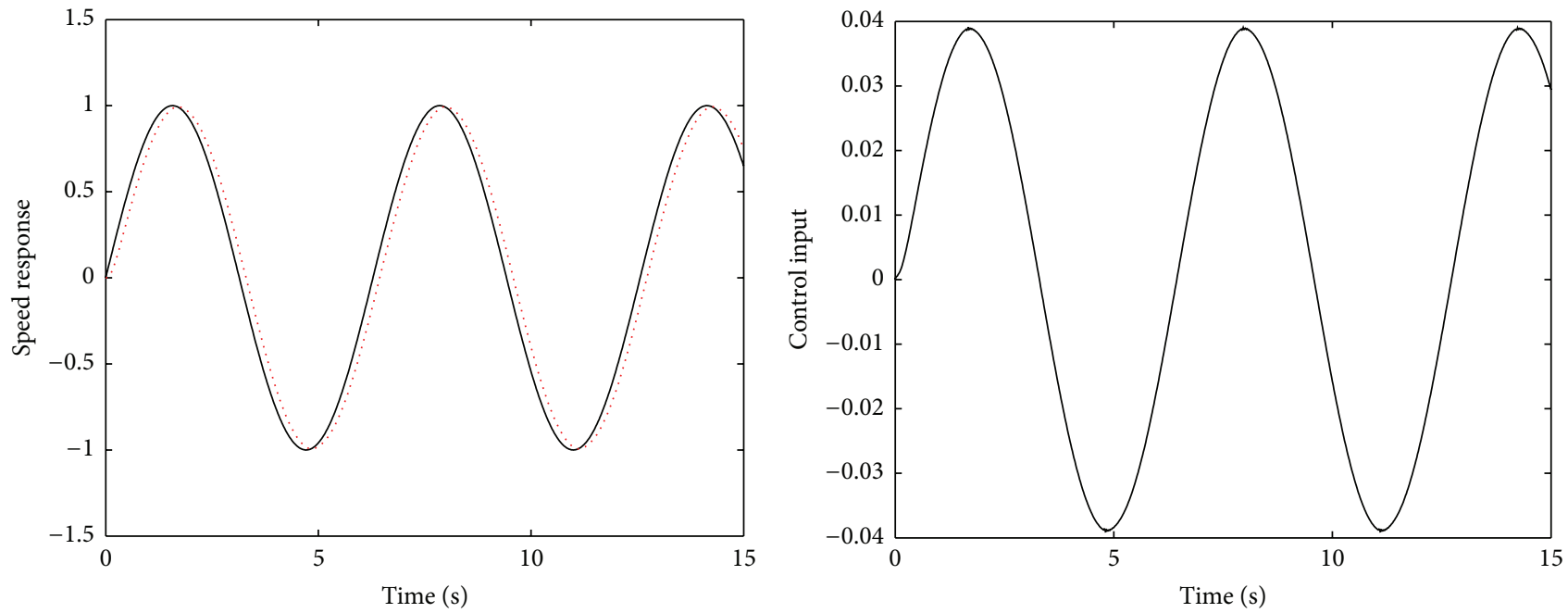

—... Ideal speed signal
Speed tracking

FIGURE 14: Simulation curve based on sliding mode control at variable speed.

The state equation of the underwater vehicle speed control system is

$$
\begin{aligned}
x_{1}= & v_{L}, \\
\dot{x}_{1}= & x_{2}, \\
\dot{x_{2}}= & -128.8 x_{1}-0.729 x_{2}+1239 u \\
& \quad-(7.87 \dot{v}+6.39 v+0.27 f) .
\end{aligned}
$$

Substituted into (35),

$$
u=\frac{1}{b_{2}}\left[\ddot{r}+c\left(\dot{r}-x_{2}\right)-a_{21} x_{1}-a_{22} x_{2}-d_{c}+\text { rlaw }\right],
$$

where the reaching law is $r$ law $=-5 \operatorname{sgn}(s)-10 s$.
The control input of sliding mode control based on reaching law may be obtained.

Figure 13 depicts digital simulation based on sliding mode control utilizing exponential reaching law. Observations from studying the speed tracking curve show that the sliding mode variable structure control law exhibits effective control for the variable structure and the variable load of the underwater vehicle speed control system. Introduction of reaching law provides the sliding mode variable structure controller improved response quality and speed tracking effects. The control input exhibits slightly high frequency chattering in the uniform motion section, negatively impacting the control object.

Variable motion simulation based on sliding mode control utilizing exponential reaching law is pictured in Figure 14. As observed from the speed tracking curve, 


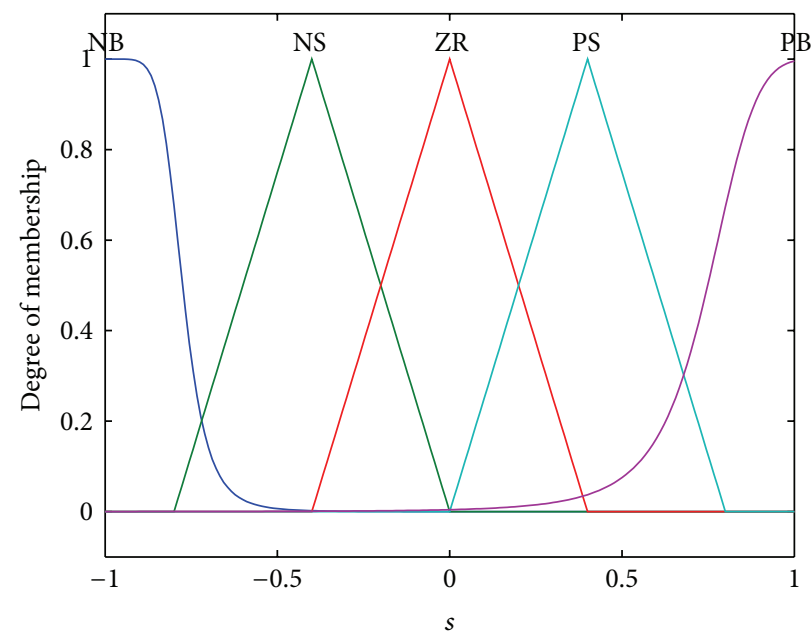

FIGURE 15: Membership function of fuzzy input $s$.

the algorithm exhibits satisfactory characteristics for interference, robustness, and control effect; however, from the control input curve, due to the switching function, substantial high frequency chattering of control input significantly impacts the actuator and control objects, adding difficulty to field trial applications.

4.4. Simulation Based on Fuzzy Sliding Mode Control. The sliding surface is $s=15 e+\dot{e}$.

The state equation of the underwater vehicle speed control system is

$$
\begin{aligned}
x_{1}= & v_{L}, \\
\dot{x}_{1}= & x_{2}, \\
\dot{x_{2}=} & -128.8 x_{1}-0.729 x_{2}+1239 u \\
& -(7.87 \dot{v}+6.39 v+0.27 f) .
\end{aligned}
$$

Substituted into (35),

$$
u=\frac{1}{b_{2}}\left[\ddot{r}+c\left(\dot{r}-x_{2}\right)-a_{21} x_{1}-a_{22} x_{2}-d_{c}+\text { rlaw }\right],
$$

where the reaching law is $r$ law $=-5 \cdot \varepsilon \operatorname{sgn}(s)-10 s$, where $\varepsilon$ is fuzzy control output.

As observed in Figures 15-17, the input and output fuzzy sets are as follows:

$$
\begin{aligned}
& s=\{\mathrm{NB}, \mathrm{NS}, \mathrm{ZR}, \mathrm{PS}, \mathrm{PB}\}, \\
& \dot{s}=\{\mathrm{NB}, \mathrm{NS}, \mathrm{ZR}, \mathrm{PS}, \mathrm{PB}\}, \\
& \varepsilon=\{\mathrm{NB}, \mathrm{NM}, \mathrm{NS}, \mathrm{ZR}, \mathrm{PS}, \mathrm{PM}, \mathrm{PB}\} .
\end{aligned}
$$

The membership function of fuzzy inputs and outputs is shown in Figures 15, 16, and 17.

Define output fuzzy rule table as [17].

Using the fuzzy rules in Table 2 to adjust the reaching law parameter $\varepsilon$ in real time, the digital simulation results are as shown in Figures 18 and 19.

Figures 18 and 19 are the digital simulation sliding mode control utilizing exponential reaching law based on fuzzy

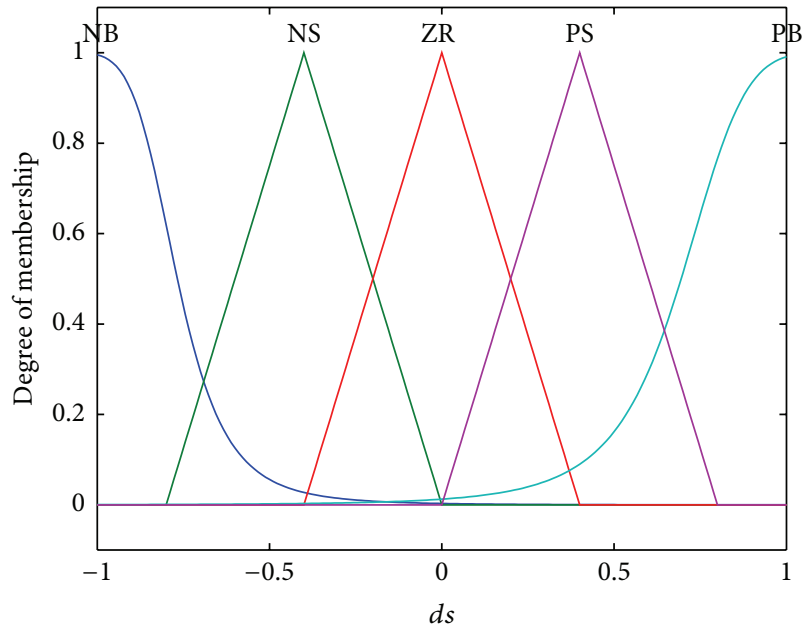

FIGURE 16: Membership function of fuzzy input $\dot{s}$.

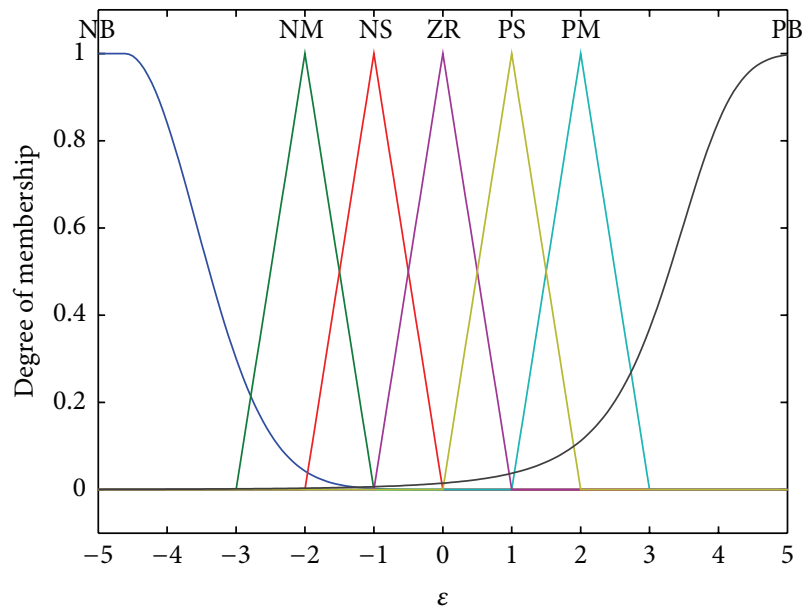

FIGURE 17: Membership function of fuzzy output $\varepsilon$.

logic. Figure 18 displays speed tracking curves of this control algorithm, demonstrating relatively effective control. The 

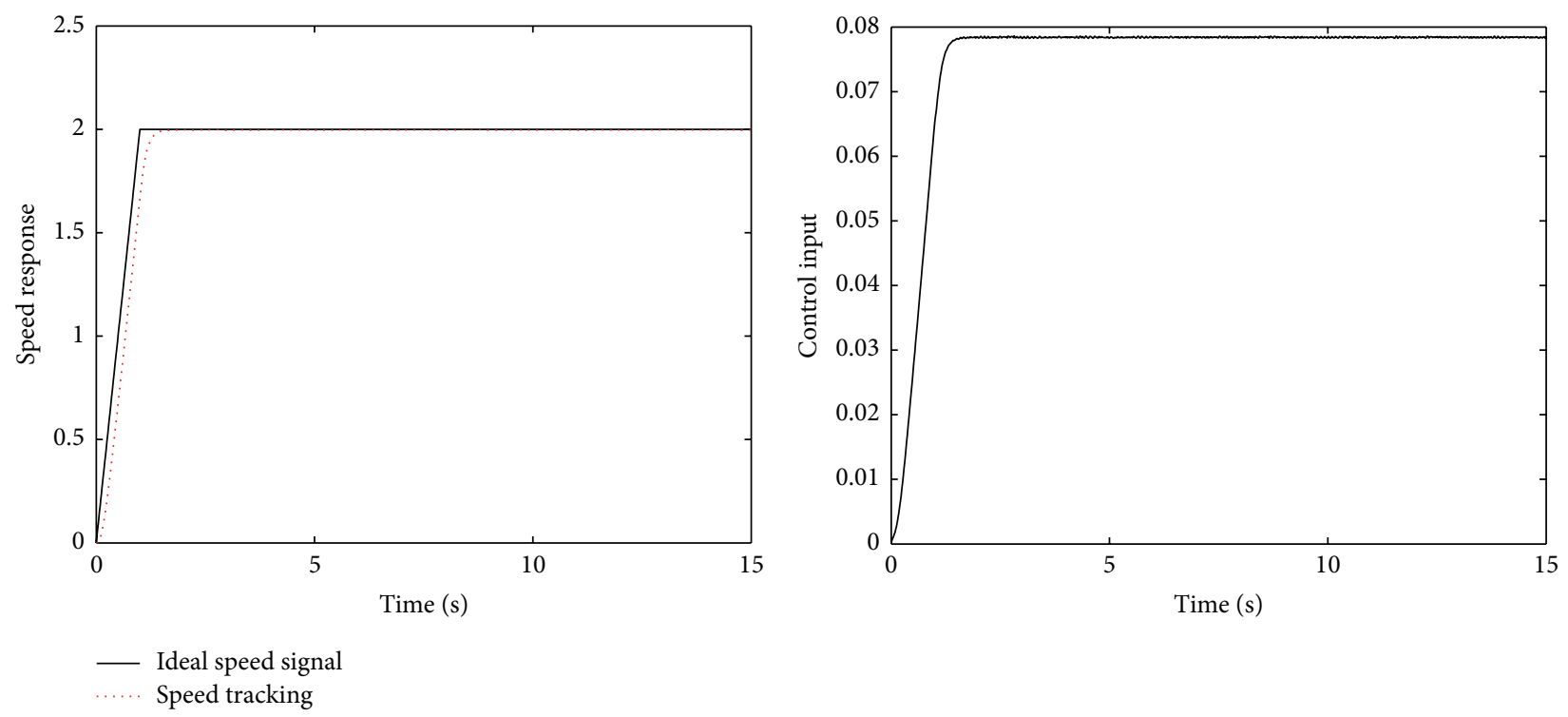

FIGURE 18: Simulation curve based on fuzzy sliding mode control at constant speed.

TABLE 2: Fuzzy rules of $\varepsilon$.

\begin{tabular}{|c|c|c|c|c|c|}
\hline & \multicolumn{5}{|c|}{$S$} \\
\hline & $\mathrm{NB}$ & NS & ZR & PS & $\mathrm{PB}$ \\
\hline \multicolumn{6}{|l|}{$\dot{S}$} \\
\hline NB & NB & NM & NS & $\mathrm{PM}$ & ZR \\
\hline NS & NM & NS & NS & ZR & $\mathrm{PM}$ \\
\hline $\mathrm{ZR}$ & NM & NS & ZR & PS & $\mathrm{PM}$ \\
\hline PS & PS & ZR & PS & $\mathrm{PM}$ & $\mathrm{PM}$ \\
\hline $\mathrm{PB}$ & ZR & $\mathrm{PM}$ & PS & $\mathrm{PM}$ & $\mathrm{PB}$ \\
\hline
\end{tabular}

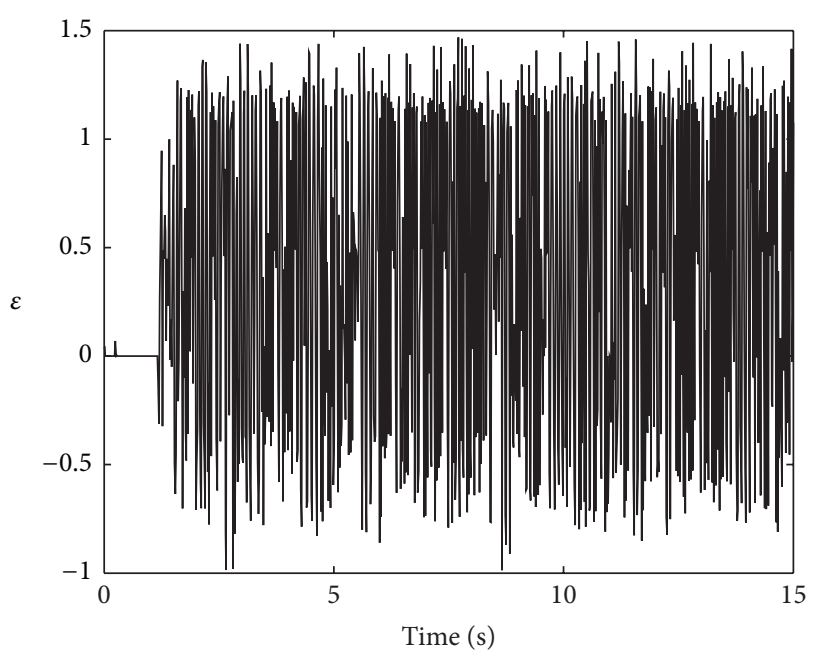

FIGURE 19: Fuzzy output $\varepsilon$.

control input characteristic curve is also shown to significantly improve compared with Figure 13. Introduction of fuzzy control theory (Figure 19) indicates smooth and stable control input with high reliability. Test results for the control algorithm also depict strong validation for the practical test.

Figure 20 displays the speed tracking curves and control input curve. Figure 21 displays the fuzzy control output characteristic curve. The control algorithm demonstrates effective control, especially related to variable speed motion control. The introduction of fuzzy control (Figure 21) smoothens the input of the control system and reveals sound output characteristics.

Digital simulations above reveal the following conclusions:

(1) Response of conventional PID algorithms for underwater variable speed motion is not sensitive. Difficulty is then experienced in meeting the requirements for precise control of the underwater vehicle.

(2) The sliding mode variable structure control system exhibits superior robustness over conventional continuous control systems. Output chattering adds difficulty, however, to variable structure control in application of the actual system.

(3) Sliding mode control of fuzzy adaptive reaching law exhibits sound robustness for overcoming disturbance and parameter uncertainties and the shortcomings of conventional sliding mode control. The system features greater control accuracy and superior realtime characteristics.

4.5. Practical Test. The underwater vehicle speed control unit calculates the opening degree value of valve based on the difference between the measured value and the given value of the underwater vehicle. The hydraulic winch propels the underwater vehicle with a closed flexible traction structure (Figure 22).

The underwater vehicle must be controlled to accelerate smoothly from the starting speed to the setting test speed and 

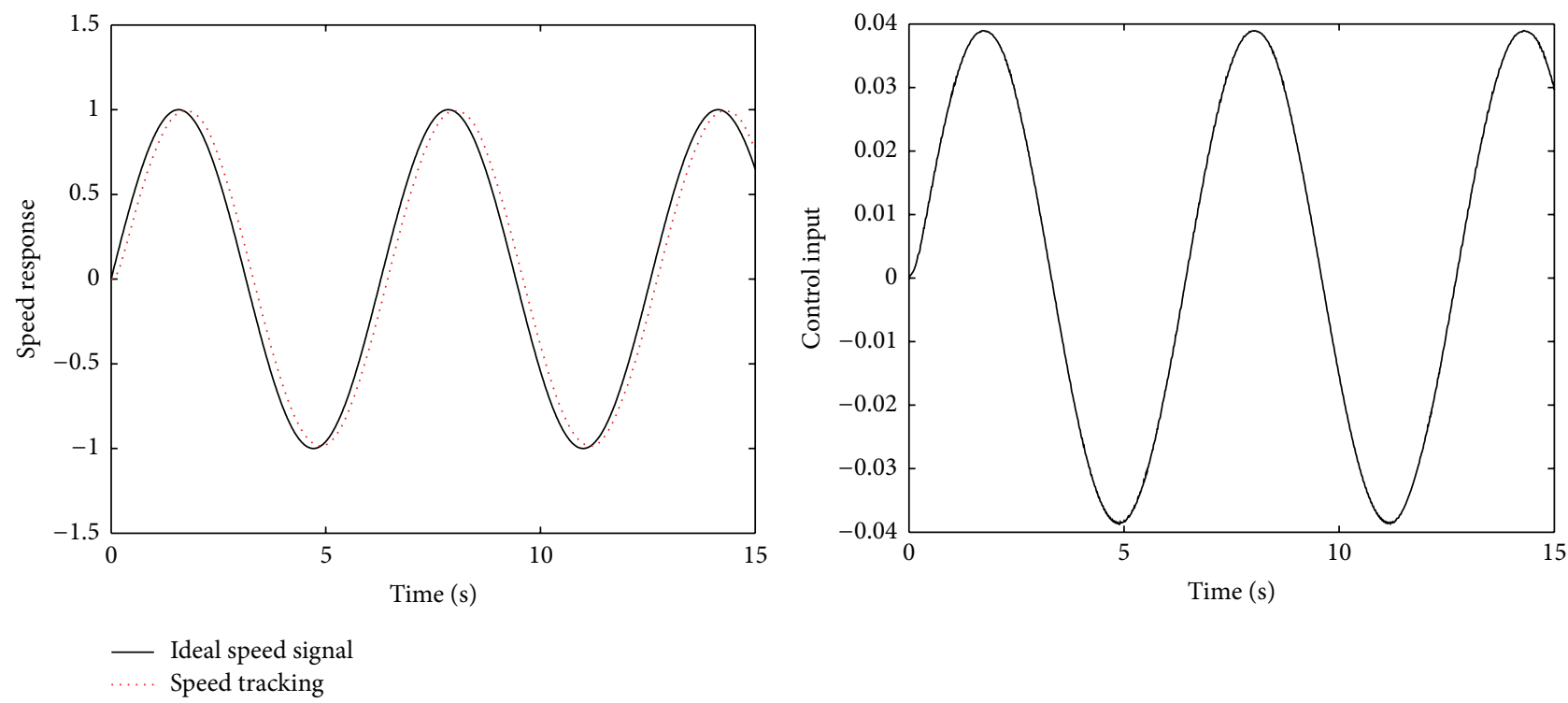

FIGURE 20: Simulation curve based on fuzzy sliding mode control at variable speed.

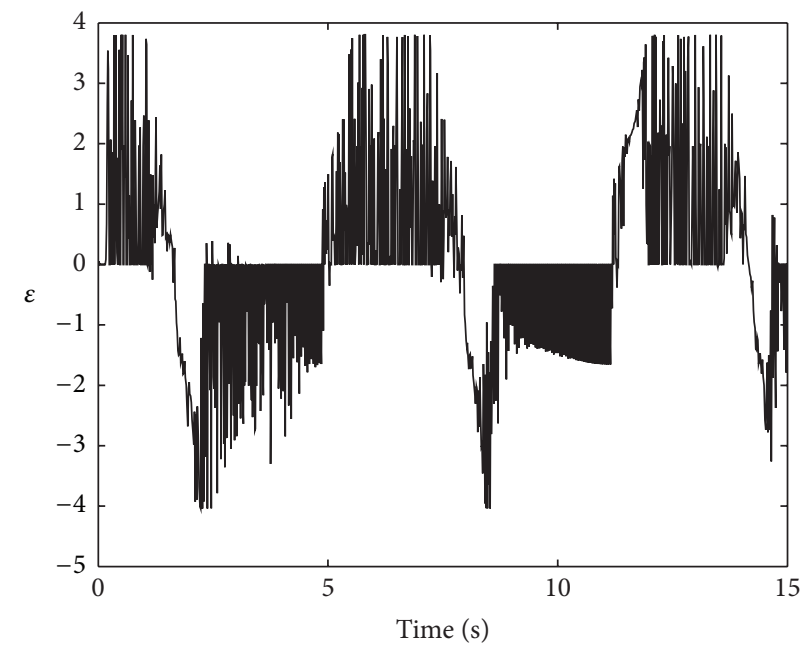

FIgURE 21: Fuzzy output $\varepsilon$.

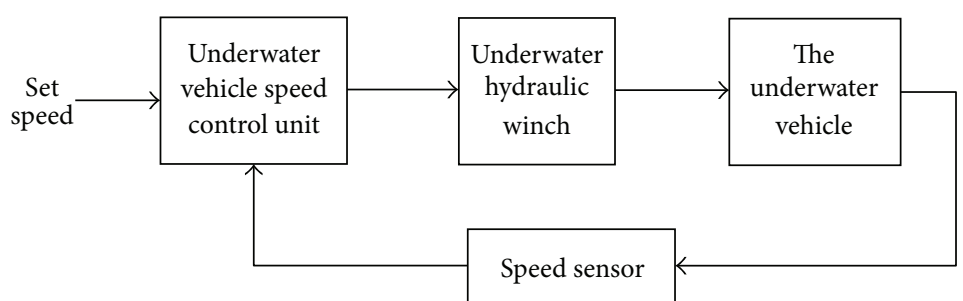

FIgURE 22: The schematic diagram of practical test.

to retain speed stability (less than $10 \%$ fluctuations). Speed of the underwater vehicle should decelerate smoothly to zero following completion of the related test. As it can be seen in Figure 23, $t_{1}$ is acceleration time, $t_{2}$ is test time, and $t_{3}$ is deceleration time.

The pictures illustrate practical testing: underwater hydraulic winch (Figure 24), underwater vehicle (Figure 25) and guide rails placed in self-submersible platform deck surface, and speed control unit (Figure 26) and underwater pump stations placed in the watertight pressure float on both sides of the platform. Siemens $400 \mathrm{H}$ redundant PLC was selected as the speed control unit processor in this study [18].

The underwater vehicle feedback speed curve is displayed at set speed $2.06 \mathrm{~m} / \mathrm{s}$ (Figure 27). The curve indicates the 


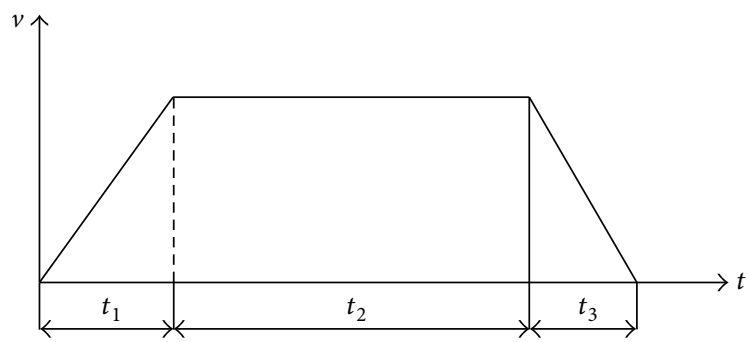

FIGURE 23: Underwater vehicle set speed curve.

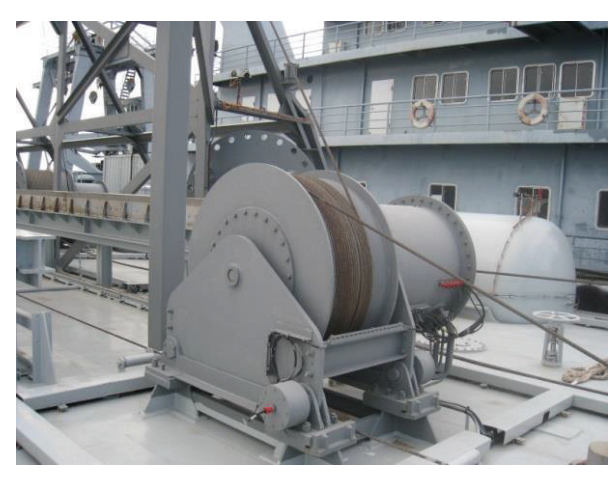

FIGURE 24: Underwater hydraulic winch.

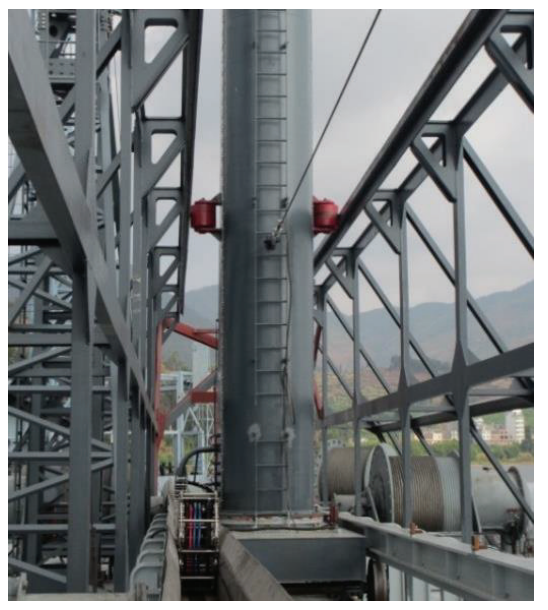

FIGURE 25: The underwater vehicle.

vehicle speed as reaching set speed in a relatively short period of time, remaining stable for a period of time to complete the test, and finally rapidly and smoothly reaching a stop. The sliding mode control based on fuzzy reaching law demonstrates effective results with the practical test.

\section{Conclusion}

Research is presented in this study based on speed control of the underwater vehicle as propelled by the hydraulic winch. Modeling analysis is conducted based on relevant features of the underwater vehicle as driven by the hydraulic winch, respectively, to the hydraulic driving system and enclosed flexible traction system. Flexibility of steel rope and features

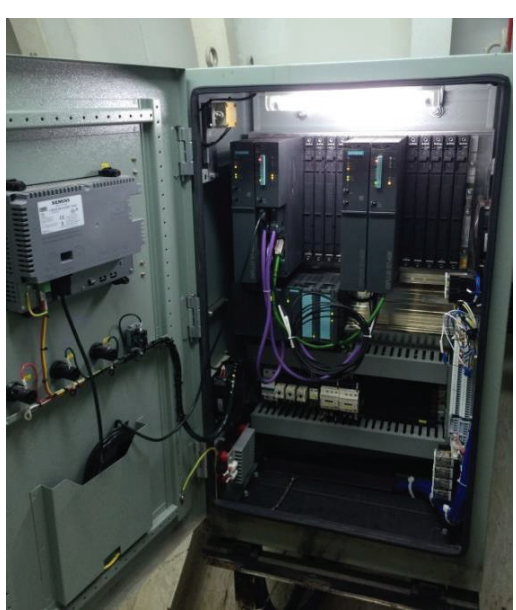

FIGURE 26: Underwater vehicle speed control unit.

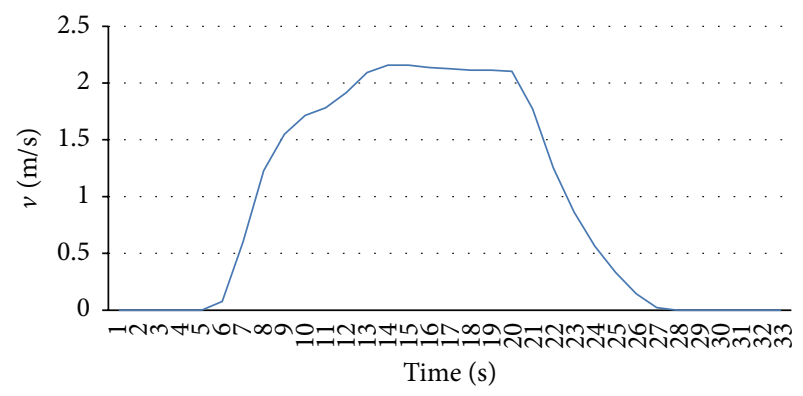

FIGURE 27: Underwater vehicle feedback speed curve.

of the hydraulic system structure reduce rigidity of the entire speed control system, increasing difficulty in speed control stability. Load of the vehicle in the movement process simultaneously presents a time-dependent nature, increasing difficulty in precise speed control. Sliding mode control algorithm based on fuzzy reaching law is then designed for the underwater vehicle speed control system with low rigidity and variable load. The sliding mode variable structure control system features superior robustness over conventional control systems. The control algorithm maintains existing features of sliding mode control, while introduction of fuzzy control law reduces output chattering caused by output switchover and stabilizing control output. Matlab mathematical simulation provided the control algorithm utilized to verify rationality and the control algorithm was realized in field tests with an ideal control effect obtained.

\section{Conflict of Interests}

The authors declare that there is no conflict of interests regarding the publication of this paper.

\section{References}

[1] B. Jin, Study on the fuzzy sliding mode control method of electrohydraulic position servo control system [Ph.D. thesis], Taiyuan University of Technology, Taiyuan, China, 2010. 
[2] D. A. Newton, "Application of a neural network controller to control a rotary drive system with high power efficiency," in Proceedings of the 7th Bath International Fluid Power Workshop, Innovations in Fluid Power, pp. 41-54, Taunton, UK, 1995.

[3] X. Zibin, M. Jianqing, and R. Jian, "Adaptive backstepping neural network control of electro-hydraulic position servo system," in Proceedings of the 2nd International Symposium on Systems and Control in Aerospace and Astronautics (ISSCAA '08), pp. 1-4, Shenzhen, China, December 2008.

[4] H. Azimian, R. Adlgostar, and M. Teshnehlab, "Velocity control of an electro hydraulic servomotor by neural networks," in Proceedings of the International Conference on Physics and Control (PhysCon '05), pp. 677-682, August 2005.

[5] I. Istif, "A simulation study for the application of two different neural network control algorithms on electro-hydraulic system," in Environmentally Conscious Manufacturing $V$, vol. 5997 of Proceedings of SPIE, pp. 599-563, Boston, Mass, USA, November 2002.

[6] S. A. Mohseni, M. A. Shooredeli, and M. Teshnehlab, "Decoupled sliding-mode with fuzzy neural network controller for EHSS velocity control," in Proceedings of the International Conference on Intelligent and Advanced Systems (ICIAS '07), pp. 7-11, IEEE, Kuala Lumpur, Malaysia, November 2007.

[7] M. Perron, J. De Lafontaine, and Y. Desjardins, "Sliding-mode control of a servomotor-pump in a position control application," in Proceedings of the Canadian Conference on Electrical and Computer Engineering, pp. 1287-1291, Saskatoon, Canada, May 2005.

[8] A. G. Loukianov, J. Rivera, Y. V. Orlov, and E. Y. Morales Teraoka, "Robust trajectory tracking for an electrohydraulic actuator," IEEE Transactions on Industrial Electronics, vol. 56, no. 9, pp. 3523-3531, 2009.

[9] R. M. Christensen, Theory of Viscoelasticity, Science Press, Beijing, China, 1990.

[10] T. W. Zur, "Viscoelastic properties of conveyor belts-modelling of vibration phenomena in belt conveyors during starting and stopping," Bulk Solids Handling, vol. 6, no. 3, pp. 553-560, 1986.

[11] H. E. Merritt, Hydraulic Control Systems, Wiley, New York, NY, USA, 1976.

[12] Y. Licai, Analysis and research of the characteristic of electrohydraulic speed servo system affected by load with large inertia and elasticity [Ph.D. thesis], Taiyuan University of Technology, Taiyuan, China, 2004.

[13] V. I. Utkin, "Variable structure systems with sliding modes," IEEE Transactions on Automatic Control, vol. 22, no. 2, pp. 212222, 1977.

[14] K. D. Young, V. I. Utkin, and Ü. Özgüner, "A control engineer's guide to sliding mode control," IEEE Transactions on Control Systems Technology, vol. 7, no. 3, pp. 328-342, 1999.

[15] W. Gao, Sliding Mode Control Theory and Design, Science Press, Beijing, China, 1996.

[16] L. A. Zadeh, "Fuzzy sets," Information and Computation, vol. 8, pp. 338-353, 1965.

[17] L. A. Zadeh, "A rationale for fuzzy control," Journal of Dynamic Systems, Measurement, and Control, vol. 94, no. 1, pp. 3-4, 1972.

[18] C.-C. Liao, S7-300/400 PLC Application Technology, China Machine Press, Beijing, China, 2014. 

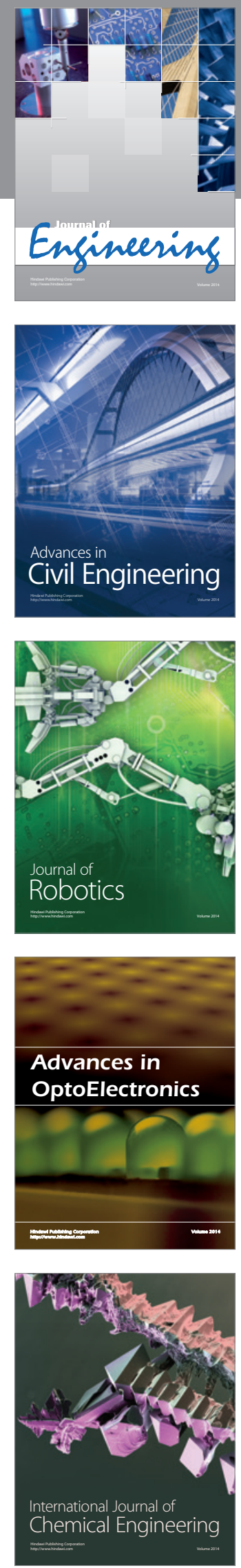

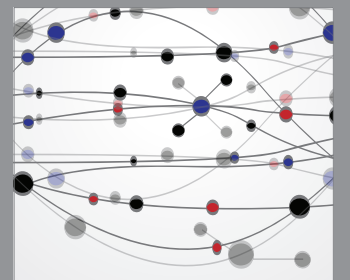

The Scientific World Journal
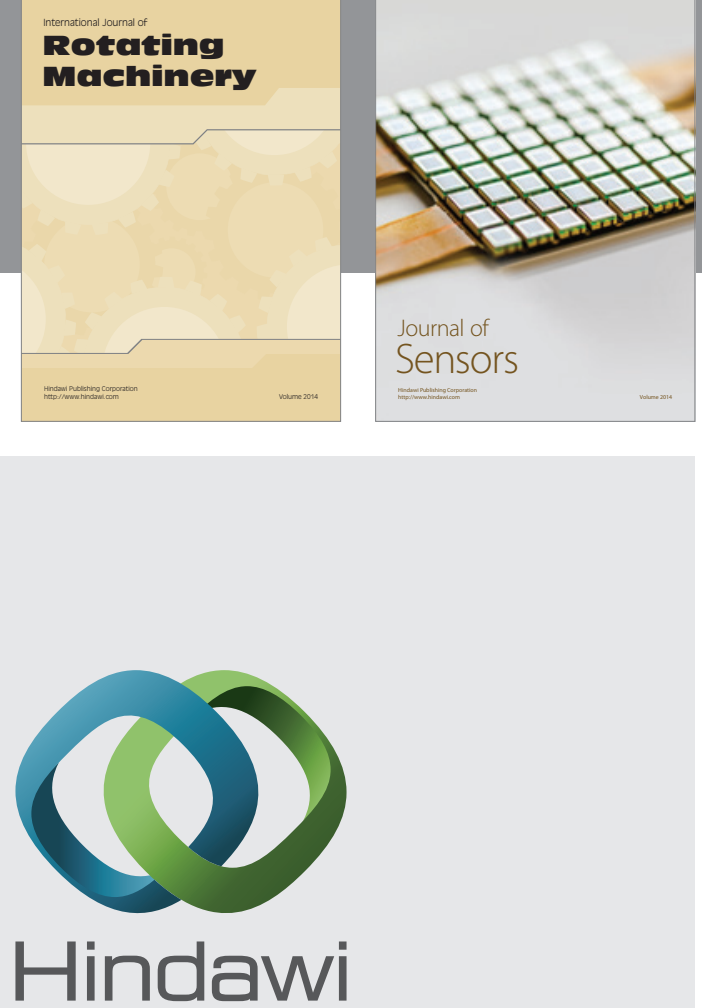

Submit your manuscripts at http://www.hindawi.com
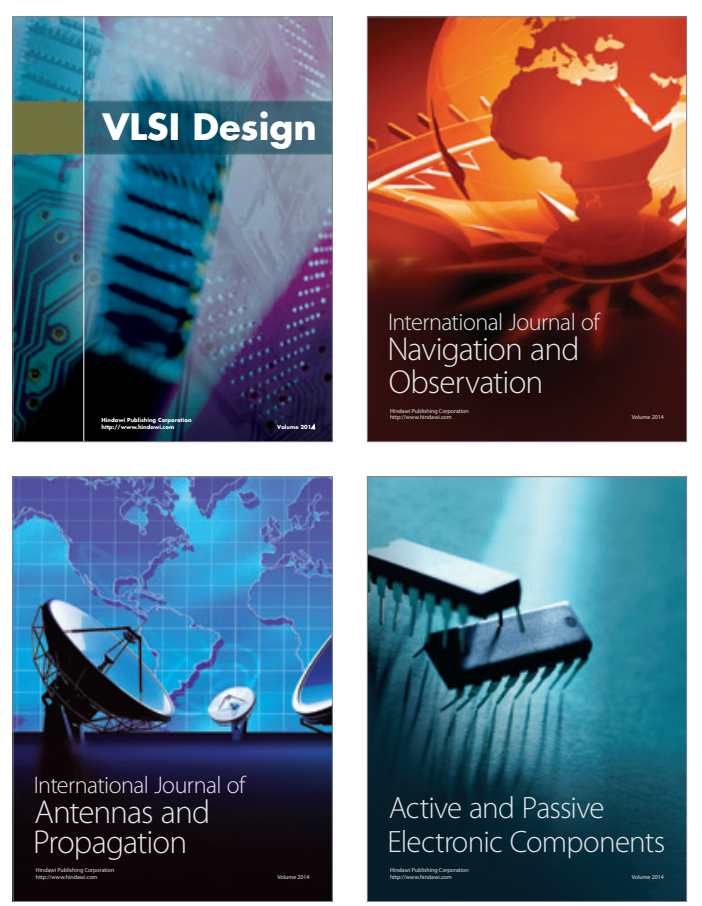
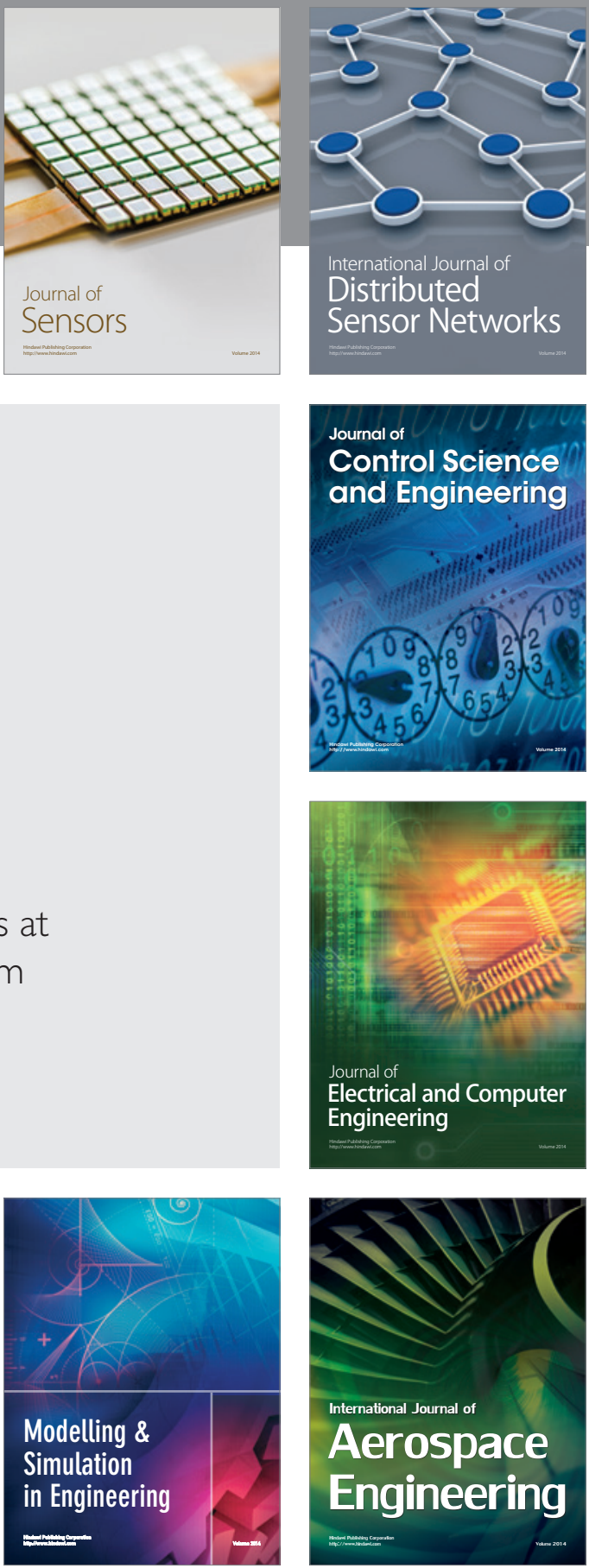

Journal of

Control Science

and Engineering
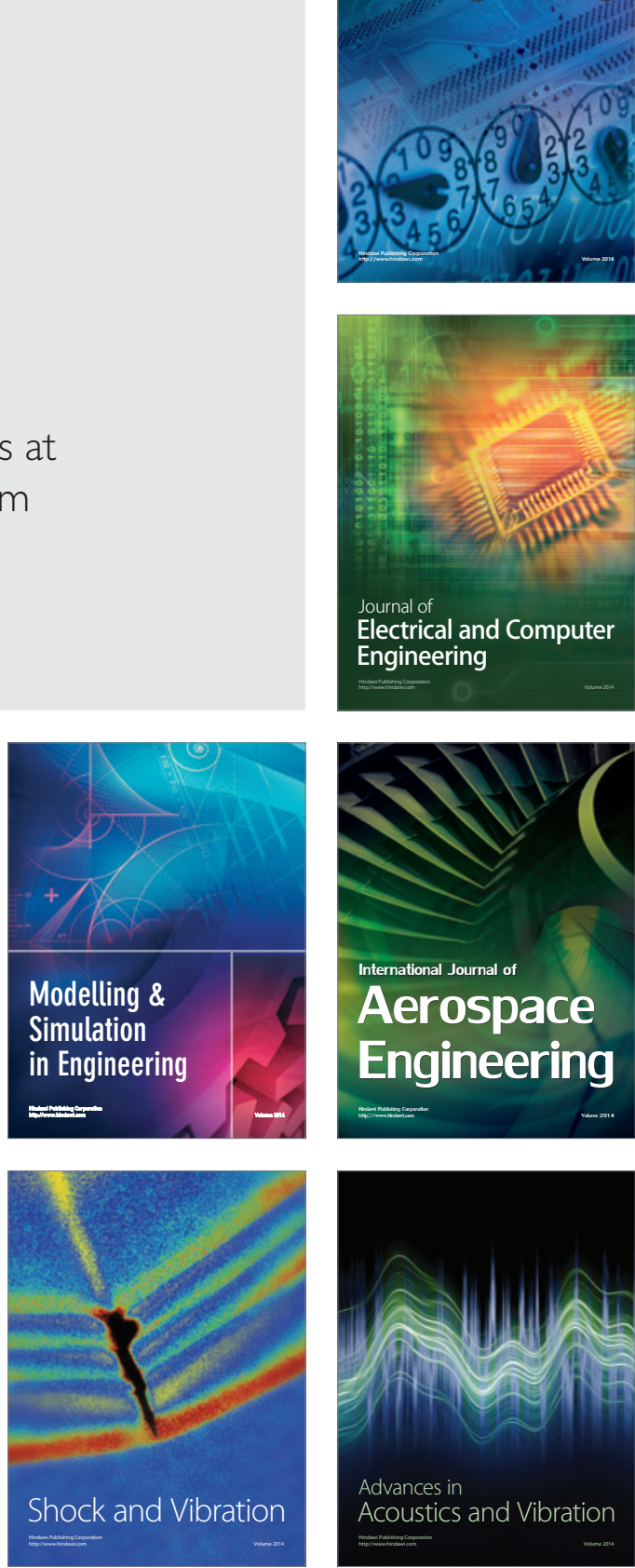